\title{
Sensitivity and Uncertainty Analysis for Functionals of the Time-Dependent Nuclide Density Field
}

M. L. Williams

C. R. Weisbin 
BLANK PAGE 
Printed in the United States of America. Available from National Technical Information Service

U.S. Department of Commerce

5285 Port Royal Road, Springfield, Virginia 22161

Price: Printed Copy \$6.00; Microfiche $\$ 3.00$

This report was prepared as an account of work sponsored by an agency of the United States Government. Neither the United Staies Government nor any agency thereof, nor any of their employees. contr dctors, subcontractors, or their employees, makes arv warranty. express or implied, nor assumes any legal liability or responsibility for a."; third party's use or the results of such use of ariy information, apparatus. product or process disclosed in this report. nor represents that its ise by such third party would not infringe privately owned rights. 
ORNL -5393

(ENDF-263)

Distribution Category UC-34c

(Physics-Nuclear)

Contract No. W-7405-eng-26

Neutron Physics Division

SENSITIVITY AND UNCERTAINTY ANALYSIS FOR FUNCT!IONALS

OF THE TIME-DEPENDENT NUCLIDE DENSITY FIELD

M. L. Williams and C. R. Weisbin

Date Published: Aprir 1978
OAK RIDGE NATIONAL LABORATORY Oak Ridge, Tennessee 37830 operated by UNION CARBIDE CORPORATION for the IEPARTMENT OF ENERGY

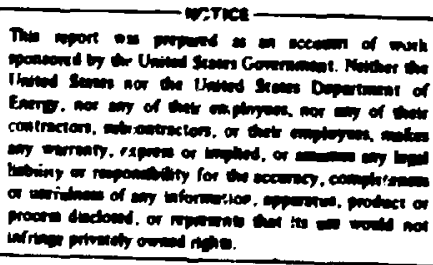


CONTENTS



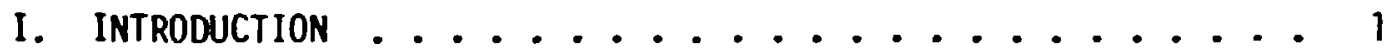

II. DERIVATION OF ADJOINT NUCLIDE FIELD EQUJATION ....... 2

III. MAGNITUDE OF ERRORS ................. 11

IV. PHYSICAL SIGNIFICANCE OF THE TIME-DEPENUENT

NUCLIDE ADJOINT ..................... 15

v. TIME-DEPENDENT UNCERTAINTY ANALYSIS .......... 18



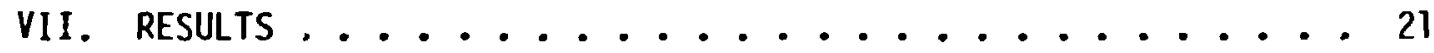

VIII. SUMAMARY AND CONCLUSIONS ............... 36

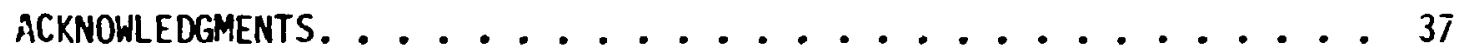

APPENDIX A. NUMERICAL SOLUTION TO THE LINEAR ADJOINT

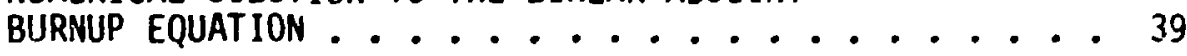

APPENOIX B. ORIGEN-A DESCRIPTION .................

APPENDIX C. ORIGEN-A CODE INPUT .............. 47

REFERENCES ........................ 70 


\section{ABSTRACT}

An approach to extend the present ORNL sensitivity program to include functionals of the time-dependent nuclide density fie?: $i$ is developed. An adjoint equation for the nucitde field has been derived previously using generalized perturbation theory; our derivation makes use of a variational principle and results in the same equation. The pinysical significance of this equation is discussed and compared to the time-dependent neutron adjoint equation. Computational requirements for determining sensitivity profiles and uncertainties for functionals of the time-dependent nuclide density vector are developed within the framework of the existing FORSS system, significantly extending the current capability. The development, testing, and use of an adjoint version of the ORIGEN isotope generation and depletion code are documented. Finally, a sample calculation is giver which estimates the uncertainty in the plutonium inventory at shutdown of a PWR ciue to assumed uncertainties in uranium and plutonium cross sections. 


\section{INTRODUCTION}

Cross section sensitivity programs at Oak Ridge $\operatorname{Re}^{1,2,3}$ and elsewhere ${ }^{4}, 5,6$ have flourished both theoretically and computationally during the last several years, culminaiing in recent uricertainty estimates' for performance parameters of large LMFBR reactors, including both differential and integral information. This work has largely been focused on the time-independent problem for functionals of the neutron flux. Previously, Gandini ${ }^{8}$ has described a formulation to enable one to compute sensitivities, and uncertainties if data covariance files are available, for linear functionals of the nuclide density field evaluated at some specified time. It is the purpose of this study to: (1) review the various derivations of equations for this research, extending the application to arbitrary time-dependent 1 inear functionals and functional ratios of the nuclide density field; (2) indicate the code development requirements for the implementation of such a procedure at ORNL; (3) present the results of a typical sample problem; and (4) indicate future directions for the current program with respect to transmutation and decay.

It should not be surprising that an adjoint equation describing the nuclide field can be formulated in a manner analogous to the procedure used by Lewins 9,10 in deriving an adjoint equation for the time-dependent neutron field. The time-r.ependent neutron and nuclide fields obey the coupled, non-linear equations commonly referred to as the depletior. equations. Over "small" time intervals these equaticns can be approximately decoupled (one assumes the neutron flux is time-independent during a depletion time interval and subsequently recalculates the flux with updated nuclide concentrations) into the linear, time-dependent Boltzmann equation and the linear, time-dependent transmutation equation. These decoupled equations look very similar: each field equation contains a linear operator (which is a function of the other field) operating on the field density and a time derivative of the field variable. Gandini 8 exploited this similitude to derive an adjoint nuclide field equation by simple analogy to the adjoint time-dependent neutron field equation, and has applied tinis equation to analytical and numerical exainples.ll our 


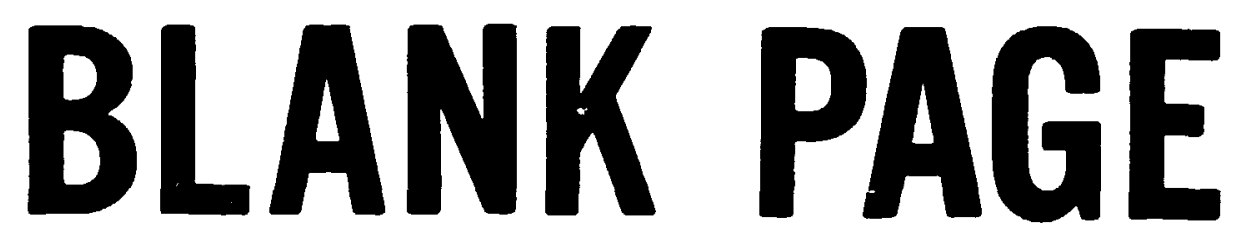


approach differs in that we derive the adjoint nuclide equation from first principles (using a variational method) and then show from phssical arguments the anaiogy to the neutron adjoint. This procedure has the advantage of handling adjoints for generalized nuclide-dependent functionals which may be of future interest (e.g., density ratios), as well as providing a rigorous foundation on wich to base our uncertainty analysis program.

The implementation of sensitivity theory at Oak Ridge for the point-depletion equation can most easily be achieved by modification of the OR:GEK'12 isotope generation and depletion code. The matrix exponential sol, ion technique employed in ORIGEN allows for straightfonward extension to solution of the time-dependent adjoint equation. Moreover, since virtually the entire nuclide data field is considered, a wide variety of questions related to the transmutation process can Ee addressed simultaneously. (Situations with significant spatial flux gradients and/or spatial nuclide gradients are best addressed with space-dependent depletion codes.) A modified version of the code designated ORIGEN-A (Appendix B) has already been developed and tested. This program is used to obtain nuclide adjoint solutions for the particular case of "final-time functionals;" its first application to sensitivity analysis is reported in this papor.

\section{DERIVATION OF ADJOINT NUCLIDE FIELD EQUATION}

The time-dependent behavior of all nuclides present in a power reactor obeys the nuclide transmutation equation given by: 13

$$
\begin{aligned}
& \underline{M}(\phi \sigma, \lambda) \underline{N}(\bar{r}, t)=\frac{\partial}{\partial t} \underline{\mu}(\bar{r}, t), t>t_{0} \\
& \underline{N}\left(\bar{r}, t_{\rho}\right) \equiv \underline{N}_{0}(\bar{r}), \quad \text { at } t=t_{0}
\end{aligned}
$$

where

$\mathbf{M}$ = the "burn-up operator," a function of nuclide microscopic reaction rates and decay constants (see Appendix $A$ ). Explicit designation of the yield (e.g., from fission) has been suppressed for convenience. 
$\underline{N}(\bar{r}, t)=$ the space-time dependent nuclide field vector whose components-- $N_{j}(\bar{r}, t), i=1$, number nuclides--represent the atom density of the $i^{\text {th }}$ nuclide at position $\bar{r}$ and time $t$.

$\underline{\Lambda}_{J}(\bar{r})=$ initial charge of nuclides in the reactor.

In reactor design studies, it is frequently desired to determine some performance parameter that is a function of the time-dependent nuclije field vector. Such an integral parameter will be referred to as a "response" in this paper. The specific types of responses which will be considered are the following:

(a) Functional of flux and atom densities evaluated at a specified instant in time (designated a "final-time functional"), $R[\phi, \underline{N}, \underline{h}]=\left\langle\underline{\phi} \underline{\underline{N}}^{\top} \underline{\underline{ }}\left(t-t_{f}\right)\right\rangle$.

(b) Functional of flux and acom densities integrated over time (designated a "time-integrated functional"),

$R[\phi, \underline{N}, \underline{h}]=\left\langle\phi \underline{h^{\top}} \underline{N}\right\rangle$.

(c) Ratio of functionals of type (a),

$$
R=\frac{\left\langle\phi_{\underline{h}}^{\top} \underline{N} \delta\left(t-t_{f}\right)\right\rangle}{\left\langle\underline{h}_{2}{ }_{N \delta}\left(t-t_{f}\right)\right\rangle} .
$$

(d) Ratio of functionals of type (b)

$$
R=\frac{\left\langle\phi \underline{h_{1}^{\top} \underline{N}}\right\rangle}{\left\langle\phi h_{2}^{\top} \underline{N}\right\rangle} .
$$

In these expressions, "T" indicates the transpose operation, and $\underline{h}$ is a "realization vector" which selects the appropriate nuclides for the response of interest. The brackets indicate integration over time, 
space, energy, and angle for reaction resporises; and $t_{f}$ is the observation time for the response. If the response is purely nuclide densities, then $\phi$ should be set to $l$ in (a)-(d), and the brackets denote integration over only space and time. In general, the $i^{\text {th }}$ component of $\underline{h}$ may be a function (eq., a reaction cross section for the $i^{\text {th }}$ nuclide in a reaction rate response), or a " 1 " (for the $i^{\text {th }}$ nuclide in a nuclide density response), or a "0" (if $i^{\text {th }}$ nuclide does not appear in the response).

For the derivations which follow, all required nuclear data such as the various $\sigma$ 's and $\lambda$ 's for each of the nuclide components of $\underline{N}$ are assembled in a collection that will be called the "reference data vector," $\underline{S}(a)$. For our purposes, the $i^{\text {th }}$ component of the data vector, $s_{i}$, corresponds to the data $a_{i}$ that appear at some location (possibly at multipie locations) in the burn-up matrix, and thus the number of components of $\underline{S}$ is equal to the number of different data parameters contained in the burn-up operator. It is the objective of our ser sitivity development to calcuiate the rate of change in the calculated response with respect to changes in the nuclear data ( $\sigma$ and $\lambda$ ) that appear in the data vector.

Consider some perturbation in a parameter denoted arbitrarily by a found in the reference nuclear data set $\underline{\mathrm{S}}$ :

$$
\underline{S^{\prime}}=\underline{S}+\delta \underline{S}
$$

due to

$$
a^{\prime}=\alpha+\delta \alpha
$$

This charge wili cause a redistribution of the time-dependent nuclide and neutron fields about their unperturbed values:

$$
\begin{aligned}
& \phi^{\prime}=\phi_{0}+\delta \phi, \\
& \underline{\mu}=\underline{N}_{0} \cdot \delta \underline{N} .
\end{aligned}
$$

The final result is a change in the response,

$$
R^{-}=R_{0}+\delta R \text {. }
$$


The perturbe 1 response is naturally a function of the "new" nuclear data set, as well as the perturbed flux and nuclide field vector.

The rate of change of the response can be expressed as a total functional derivative ${ }^{14}$ with respect to $\alpha$ :

$$
\frac{d R}{d \alpha}=\left\langle\left(\frac{\partial R}{\partial \underline{h}}\right)^{T} \frac{d \underline{h}}{d \alpha}+\left(\frac{\partial R}{\partial \underline{N}}\right)^{T} \frac{d \underline{N}}{d \alpha}+\frac{\partial R}{\partial \phi} \frac{d \phi}{d \alpha}\right\rangle .
$$

In this expression the vector derivatives are defined by

$$
\left(\frac{\partial R}{\partial \underline{h}}\right)^{\top}=\left(\frac{\partial R}{\partial h_{1}}, \frac{\partial R}{\partial h_{2}}, \frac{\partial R}{\partial h_{3}}, \text { etc. }\right) \text {. }
$$

The first term of Eq. (8) represents the direct effect, or change in the response due to a change in a cross section appearing explicitly in the response definition. Hence the evaluation of these derivatives is straightforward. In the current work, the third term in Eq. (8) is neglected by assuming that small perturbatiors in nuclear data do not severely distort the time-dependent flux behavicr. Recently Kallfelz has suggested a method ${ }^{15}$ that can partially account :or this effect using static, generalized perturbation theory applied over a series of time intervals. However, this procedure has not been incorporated in the present analysis, which is restricted to point-depletion. The major effort, therefore, lies in formulating an expression for the change in response $R$ due to a change in a nuclear data element which affects the transmutation process and, thus, the nuclide field concentrations.

Consider the second term of Eq. (8), with the assumption that the flux field remains unchanged over the time interval of interest $\left(t_{n}, t_{f}\right)$. The value for $d N / d a$ can be found by implicit differentiation of the nuclide field equation:

$$
\frac{d}{d x}\left(M \underline{N}-\frac{\partial}{\partial t} \underline{N}\right)=\frac{\partial M}{\partial \alpha} \underline{N}+M \frac{d \underline{N}}{d x}-\frac{\partial}{\partial t} \frac{d \underline{N}}{d \alpha},
$$


assuming that ail required derivatives exist. Rearranging gives the following:

$\underline{\underline{M}}\left(\frac{\mathrm{d} \underline{ }}{d \alpha}\right)=\frac{3}{\partial t}\left(\frac{d \underline{N}}{d \alpha}\right)-\frac{\partial \underline{\underline{M}}}{\partial \alpha} \underline{N}$

If we defire an auxiliary equation of the form

$$
\underline{\underline{M}}^{*} \underline{\underline{N}}^{\star}=\frac{-g}{\partial t} \underline{\underline{\mu}^{*}}+\frac{\partial R}{\partial \underline{R}} \text {, where } \underline{\underline{M}}^{*}=M^{\top} \text {, }
$$

then Eq. (9) and (10) can be combined to give

$$
\left\langle\frac{\partial}{\partial t}\left(\frac{d \underline{N}^{\top}}{d a} \underline{N}^{\star}\right)\right\rangle+\left\langle\frac{\partial R}{\partial \underline{N}} \frac{d \underline{N}}{d a}-\underline{N}^{\star T} \frac{\partial \underline{\underline{M}}}{\partial a} \underline{N}\right\rangle=0
$$

Finally, solving for the second term in (8):

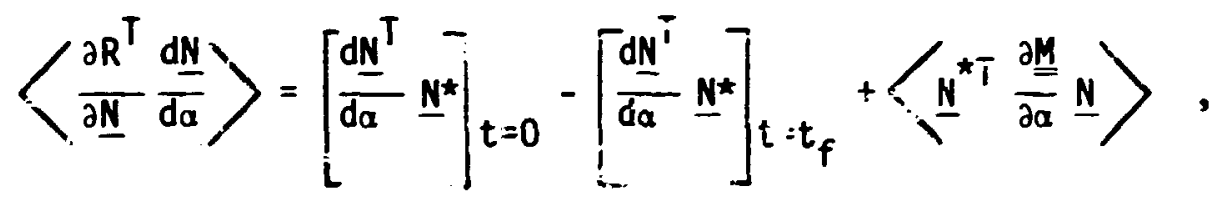

with the first two terms on the RHS ir.tegrated over space.

We can assL 7 that $(\mathrm{d} N / d \alpha)_{t=0}$ is zero, since $\underline{N}_{0}$ is specified independrant of $a$. With the additional concition that $\underline{N}^{\star}\left(t_{f}\right)=0$, the governing equation for $\underline{N}^{*}$ is specified to be a fir.al value probiem. [Note however that if $R$ is d delta-function, the source in Eq. (10) is equivalent to a non-homogeneous final condition.] It will later be shown that $\mathrm{N}^{*}$ is the "nuclide adjoint function." From (12), the second terin of Eq. (8) redices simply to

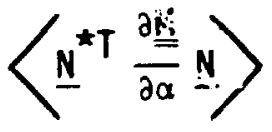

The preceding brief diuivation, which was based on determining the "slope" of the response in a-space, is useful in fllustrating the physical 
procedure inyolved in sensitivity theory. However, this differential development wiil not be pursued further in this paper. Instead we wili employ an aliernate technique (that produces equations similar to those previously derived) for which the error approximations inherent in sensitivity analysis are more apparent.

In the evaluation of the second term of Eq. (8) a formulation is sought which is insensitive to first order errors in the change in nuclide density, i.e.,

$$
\delta R=\left[a \delta+b \delta \underline{N}^{2}\right] .
$$

The increment $\delta R$ is first order in $\delta a$ but second order in $\delta \underline{N}$. It is then only necessary to evaluate the coefficient " $a$ " of $\delta \alpha$ to obtain estimates of $\delta R$ accurate through first order in $\delta \underline{N}$.

A systematic procedure based on a variational principle has been suggested by Promraning ${ }^{i 6}$ and 5 tacey ${ }^{77}$ to achieve this stationary condition. With this method, the transmutation equation is treated as a constraint condition on the response; and as such, is appended to the functional with an unspecified Lagrange multiplier $\underline{N}^{\star}$ :

$$
K\left[\phi, \underline{h}, \underline{N}, \alpha, N^{\star}\right]=R[\phi, \underline{h}, \underline{N}]+\left\langle\underline{N}^{\star T}\left[\underline{M}(\alpha) \underline{N}-\frac{\partial N}{\partial t}\right]>\right.
$$

The explicit dependence on $\bar{r}$ and $t$ has been suppressed where convenient. The $K$ functional is an explicit function of all the data parameters found in the "data vector" $\underline{S}$, since these values are contained in the operator.

From Eq. (15) we see that if the unperturbed value for $\underline{N}$ [i.e., the solution to $\underline{\underline{M}} \underline{N}=\frac{\partial}{\partial t} \underline{N}, \underline{N}(0)=\underline{N}_{0} \mid$ is used to evaluate $K$, then

$$
K\left[\phi, \underline{h}, \underline{N}, \alpha, \underline{N^{\star}}\right]=R .
$$

Furthermore, if $\alpha^{\prime}$ and $\underline{N}^{-}$are perturbed values that obey the relation

$$
\underline{\underline{M}}^{\prime}\left(x^{-}\right) \underline{N}^{-}=\frac{\partial}{\partial t} \underline{N}^{\prime}, \underline{N}^{-}(0)=\underline{N}_{0}^{\prime},
$$


then

$$
K^{-}\left[\phi, \underline{h}, \underline{N}^{-}, \alpha^{-}, \underline{N}^{*}\right]=R^{-} \text {. }
$$

where $\underline{N}^{\star}$ is as yet an unspecified Lagrange function evâluated using data set $a$. For purposes of evaluating the second term of Eq. (8), $\phi$ and $\underline{h}$ are unaffected by data set alteration $\left(\alpha^{*}\right)$.

Expanding the left-hand side of Eq. (18) in a function Taylor series about the unperturbed variables and suppressing the $\phi$ and $\underline{h}$ dependence gives

$$
\begin{aligned}
K^{\prime}=K\left[\phi, \underline{h}, \underline{N}, \alpha, N^{\star}\right] & +\left\langle\left(\frac{\partial K}{\partial \underline{N}}\right)^{\top}\left(\underline{N}^{\prime}-\underline{N}\right)+\left(\frac{\partial K}{\partial \underline{N}^{\star}}\right)^{\top}\left(\underline{N}^{\star-}-\underline{N}^{\star}\right)\right. \\
& \left.+\frac{\partial K}{\partial \alpha}\left(a^{\prime}-\alpha\right)\right\rangle \therefore \ldots \text { higher cerms. }
\end{aligned}
$$

If the pertial derivatives $\frac{\partial K}{\partial \underline{N}}$ and $\frac{\partial K}{\partial \underline{N}^{\star}}$ can be made to yanish, then using Eqs. (16), (18), and (19)

$$
\begin{aligned}
R^{-}-R=\left\langle\left(\frac{\partial K}{\partial \alpha}\right)_{\underline{\underline{N}, \underline{N}^{*}}}\left(\alpha^{-}-\alpha\right)\right\rangle \\
\quad+\text { second-order terms in }(\delta \underline{N}),\left(\delta \underline{N}^{\star}\right)
\end{aligned}
$$

which is the desired result.

To determine the appropriate stationary conditions, consider first the variation of $\mathrm{K}$ with respect to $\mathrm{N}^{\star}$ (i.e., the 3rd term on the righthand side of Eq. 19):

$$
(\delta K)_{\delta \underline{N}^{\star}}=\left(\frac{\partial K}{\partial \underline{N}^{\star}}\right)^{\top} \cdot \delta \underline{N}^{\star}=\left\langle\delta \underline{N}^{\star T}\left|\underline{M} \underline{N}-\frac{\partial}{\partial t} \underline{N}\right|>,\right.
$$

which gives the expected Euler condition

$$
\underline{M} \underline{N}=\frac{\partial}{\partial t} \underline{N} \text {. }
$$


The solution to the unperturbed turn-up equation (Eq. 22) makes $K$ stationary with respect to arbitrary variations in the function $\underline{N}^{*}$.

Taking the variation with respect to $\underline{N}$ (i.e., the second term on the right-hand side of Eq. 19 ) gives



$$
\begin{aligned}
& \int-j \underline{\underline{N}} \underline{N}^{\top}\left(t_{f}\right) \underline{N}^{\star}\left(t_{f}\right)+\delta \underline{N}^{\top}\left(t_{0}\right) \underline{N} \star\left(t_{0}\right) d \dot{t}
\end{aligned}
$$

In obtaining the above equation, the following adjoint properties were employed:

$$
\left\langle\underline{N}^{\star T} M \underline{N}\right\rangle=\left\langle\underline{N}^{\top} M^{\star} \underline{N}^{\star}\right\rangle
$$

where $M^{\star}=$ transpos $\subseteq M$, and

$$
\begin{aligned}
\int_{t} \underline{N}^{* T} t \underline{N} d t & =\underline{N}^{\top}\left(t_{f}\right) \underline{N}^{\star}\left(t_{f}\right) \\
& -\underline{N}^{T}\left(t_{0}\right) \underline{N}^{\star}\left(t_{0}\right)-\int_{t} N^{\star \top} \frac{N^{\star}}{i t} \underline{N}^{*},
\end{aligned}
$$

where $t_{f}$ is the final time in the time domain for $\underline{N}$.

A.t this point, there are several ways of reducing the expression in Eq. (23), the appropriate method depending on the specific response of interest. For example, consider the case of the response being a final-time, linear functional at $t_{f}$ (i.e., response type "a"). Then

$$
\begin{aligned}
& \frac{i R}{i \underline{N}}=\int_{E} \int_{.:} \underline{h}_{F}(t) d \delta d E \hat{i}\left(t-t_{f}\right)=\begin{array}{l}
\text { spare-dependent } \\
\text { delta function } ;
\end{array} \\
& \int \frac{N}{\top} \frac{\delta R}{\delta \underline{N}} d V=\delta \underline{N}^{\top}\left(t_{f}\right) \int_{E} \int \underline{h} \neq\left(t_{f}\right) d d E d V
\end{aligned}
$$


If we set $\left.\underline{N}^{*}\left(t_{f}\right) \equiv N_{f}^{*} ! r\right)=\int_{E} \int_{\Omega} t_{\phi}\left(t_{f}\right) d \Omega d E$, then the $\delta \underline{N}\left(t_{f}\right)$ boundary term vanishes in equation (23). Excluding the initial condition perturbation $\delta \underline{N}_{0}$, the remainder of the expression for $\delta K$ will vanish if $\mathbb{N}^{*}$ obeys the final value equation.

$$
\underline{\underline{M}}^{*} \underline{N}^{*}=\frac{-\partial}{\partial t} \underline{N}^{*}, \underline{N^{*}}\left(t_{f}\right)=\underline{N_{f}^{*}}
$$

If the response $R$ is a ratio specified at $t=t_{f}$ (response type " $c$ "), then Eq. (28) still ho?ds, but the final condition is now

$$
\begin{array}{r}
N_{f}^{*}(r)=\frac{\left\langle\underline{N}^{\top} \underline{h}_{1} \phi \delta\left(t-t_{f}\right\rangle\right\rangle}{\left\langle\underline{N}^{\top} \underline{h}_{2} \phi \delta\left(t-t_{f}\right)\right\rangle}\left\{\frac{\int_{E} \int_{\Omega} \phi\left(t_{f}\right) \underline{h}_{1} d \Omega d E}{\left\langle\underline{N} \underline{h}_{1} \phi \delta\left(t-t_{f}\right)\right\rangle}\right. \\
\left.-\frac{\int_{E} \delta_{\Omega}^{\phi}\left(t_{f}\right) h_{2} d \Omega d E}{\left\langle\underline{N}^{\top} \underline{h}_{2} \phi \delta\left(t-t_{f}\right)\right\rangle}\right\} .
\end{array}
$$

For the case of a time-integrated, linear functional (response type "D"), the $\delta \underline{N}\left(t_{f}\right) t \in m$ is made to vanish by choosing $N_{f}(r)=0$. The appropriate condition for $\underline{N}^{\star}$ is now an inhomogeneous equation with a homogenecus final condition,

$$
\begin{aligned}
& M^{\star} \underline{N}^{*}=-\frac{\delta}{\delta \underline{N}^{*}}-\underline{Q}^{*} \\
& \underline{H}^{*}(r)=0,
\end{aligned}
$$

where the time-dependant fixed source is defined by

$$
\underline{Q}^{\star}(r, t) \equiv \frac{\partial R}{\partial \underline{R}}=\int_{E} \int_{\Omega} \phi(t) \underline{h d} 2 \partial \mathrm{dE} .
$$


For the irtegrated functional ratio (response type "d"), Eq. (30) still holds, but now

$$
\underline{Q}^{*}=\frac{\left\langle\underline{N}^{\top} \underline{h}_{1}\right\rangle}{\left\langle\underline{N}^{\top} \underline{h}_{2} \phi\right.}\left\{\frac{\int_{E} \int_{\Omega}^{\phi(t) \underline{h}_{1} d \Omega d E}}{\left\langle\underline{N}^{\top} \underline{h}_{1}\right\rangle}-\frac{\int_{E} \int_{\Omega} \phi(t) \underline{h}_{2} d \Omega d E}{\left\langle\underline{N}^{\top} \underline{h}_{2} \phi\right\rangle}\right\} .
$$

With the equations for the adjoint nuclide field defined by the methods discussed, it is now possible to write (for an unperturbed flux field)

$$
\Delta R=\left\langle\frac{\partial R}{\partial \alpha} \delta \alpha\right\rangle+\left\langle\left(\underline{N}^{\star T} \frac{\partial}{\partial \alpha} \underline{\underline{M}} \underline{N}\right) \delta \alpha>+\int_{\delta \underline{N}_{0}} \underline{\underline{N}} \underline{\underline{N}} d V .\right.
$$

Note that $R$ can be evaluated for any $\delta \alpha\left(\alpha\right.$ in $\underline{\jmath}$ ) and for any $\delta \underline{N}_{0}$, withsut requiring a new calculation for $\underline{N}$ and $\underline{N}^{*}$, and in this property lies the power of the perturbation approach to sensitivity analysis. For no change in the iritial condition, Eq. (33) refuces to the response change arising from data changes only, previously derived in Eq. 13.

\section{MAGNITUDE OF ERRORS}

The burn-up operator $M(\sigma \phi, \lambda)$ can be written as the sum of two operators, one representin! nuclide transmutation by radioactive decay, the other transmutation by reactions with the neutron field:

$$
M(\sigma \phi, \lambda)=R(\sigma \phi)+\underline{\underline{D}}(\lambda)
$$

A change in some nuclear data value will result in

$$
\begin{aligned}
\delta \underline{\underline{M}} & =\underline{\underline{R}}(\delta(\sigma \phi))+\underline{\underline{D}}(\delta \lambda)=\frac{\partial \underline{\underline{R}}}{\partial \sigma} \delta \sigma+\frac{\partial \underline{\underline{R}}}{\partial \phi} \delta \phi+\frac{\partial \underline{\underline{R}}}{\partial \lambda} \delta \lambda \\
& + \text { 2nd order term in } \delta \phi \text { and } \delta \sigma
\end{aligned}
$$


In particular, note that there is a perturbation in the reaction rate operator due to the flux change $\delta$. Since the flux field is a function both of the data appearing explicitly in the Boltzmann equation, and of the nuclide field vector, a change in either or both of these variables will affect the flux; e.g., a change in data containec in the burn-up operator (and possibly also contained in the Boltzmann operator) will perturb the nuclide field, which then alters the flux field. This flux change is fed back as additional perturbation to the burn-up operator, and so on. For the present study, we will neglect this nonlinearity and assume that any ciranges to the nuclear data parameters contained in the burn-up operator do not significantly affect the neutron field, so that over some time period

$$
\delta \underline{\underline{M}} \cong \phi \underline{\underline{P}}(\delta \sigma)+\underline{\underline{D}}(\delta \lambda)
$$

It should be pointed out that the $\delta \phi$ term is a first-order error and therefore an estimate of the response change based on equation (33) may be inaccurate for data uncertainties which se"-rely distort the time-dependent flux over the time interval of interest. If one requires first-order accuracy to variations in both fields simultaneously, coupled neutron-nuclide perturbation theory must be employed.

To illustrate the role of the nuclide adjoint function in is $i$-order perturbation theory, an al ternate derivation of Eqs. (26) and (33) will now be presented. ${ }^{(a)}$ For this approach, we chose to write a specified final-value response functional $R[\underline{N}]=\left\langle\underline{h^{\top}} \underline{N}\left(t_{f}\right) \delta\left(t-t_{f}\right)\right\rangle$ as follows

$$
R\left[\underline{N]}=\int_{t_{0}}^{t_{F}} \frac{d}{d t}\left(\underline{N}^{\top} \underline{N}^{\star}\right) d t+\underline{N}^{* T}\left(t_{0}\right) \underline{N}\left(t_{0}\right),\right.
$$

${ }^{(a)}$ See reference 10 for the neutron analog. 
where $\underline{N}^{*}$ is an unspecified function in the domain of continuous functions on $\left[t_{0}, t_{f}\right]$, the only requirement being a fixed end point of $\underline{N}\left(t_{f}\right)=\underline{h} \hat{*}$. Phase space variables otmer than "time" are not explicitly treated in this developsent; integration over these variables is assumed. Expanding Eq. (j7),

$$
\begin{aligned}
& R[\underline{N}]=\int_{t_{0}}^{t_{f}}\left(\underline{N}^{T \star} \frac{d \underline{N}}{d t}+\underline{N}^{T \frac{d \underline{N}^{*}}{d t}}\right) d \dot{t}+\underline{N}^{T \star}\left(t_{c}\right) \underline{N}\left(t_{0}\right) \\
& =\int_{t_{0}}^{t_{f}}\left[\left(\underline{N}^{T^{\star}} \underline{\underline{M}} \underline{N}\right)+\underline{N}^{T^{d N^{*}}}\right] d t+\underline{N}^{T^{\star}}\left(t_{0}\right) \underline{N}\left(t_{0}\right) .
\end{aligned}
$$

He will now consider a perturbation in the nuclide field equation le.g., due to data change):

$$
\underline{M}-\underline{N}=\frac{\dot{\partial}}{\partial t} \underline{N}
$$

and Eq. (39) becomes

$$
R^{-}\left(N^{-}\right)=\int_{t_{0}}^{t_{f}}\left(N^{\star} T^{-N^{-}}+\underline{N}^{-T} \frac{d}{d t} \underline{N}^{*}\right) d t+\underline{N}^{\star T}\left(t_{0}\right) \underline{N}\left(t_{0}\right)
$$

(assuming no change in the initial concentrations $\underline{N}_{0}$ or the realization vector $\underline{h}$ ). Therefore, we see that

$$
\begin{gathered}
R^{\prime}\left(\underline{N}^{-}\right)=\int_{t_{0}}^{t_{f}}\left(\underline{N}^{\star T} M_{N^{-}}+\underline{N}^{\star T} \delta M \underline{N}+\underline{N}^{\star T} \delta \underline{M} \delta \underline{N}+\underline{\left.N^{T} \cdot \frac{d N^{*}}{d t}\right) d t}\right. \\
+\underline{N}^{\star T}\left(t_{0}\right) \underline{N}\left(t_{0}\right) .
\end{gathered}
$$

Applying the adjoint propert.y to the $M$ and $\frac{d}{d t}$ operators, 


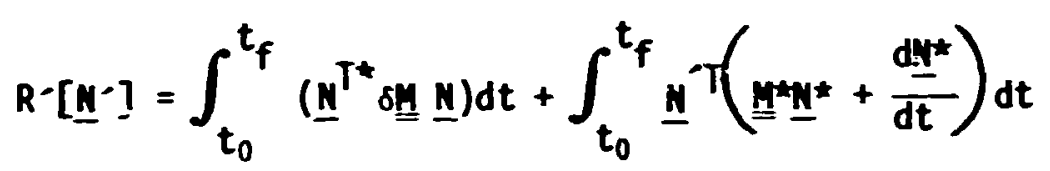

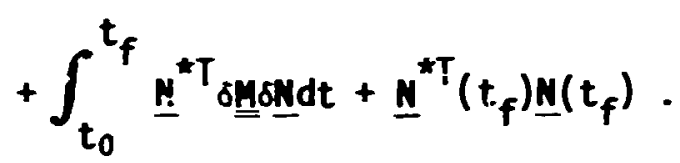

Recall that up until this point, N has been an arbitrary function. We will now define it as the function wich causes the second integral to vanish, i.e.,

$$
\begin{aligned}
& \underline{M}^{*} \underline{N}^{\star}=-\frac{d}{d t} \underline{N}^{\star} \\
& \underline{N}^{\star}=\underline{h}, \quad \text { at } t=t_{f} .
\end{aligned}
$$

of course this is merely a restatement of Eq. (28). By definition,

$$
\underline{N}^{* T}\left(t_{f}\right) \underline{N}\left(t_{f}\right)=\underline{N}^{T}\left(t_{f}\right) \underline{h}=R[\underline{N}] .
$$

Substituting the above relation into Eq. (43) gives the following

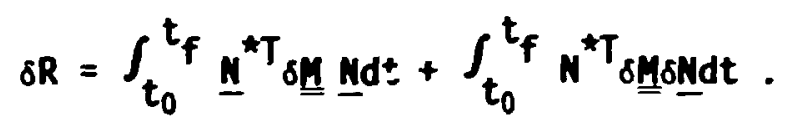

Since the last integral in $\mathrm{Eq} .(45)$ is second order, we see that N is that particular function wh ch makes the response in Eq. (37) insensitive (to first order) to variations in $\underline{N}(t)$. Finally, we can say

$$
\delta R=\int_{t_{0}}^{t_{f}} \underline{N}^{\star T} \delta \underline{N} \underline{\text { Nd }} \text { plus 2nd order terms. }
$$


IV. PHYSICAL SIGNIFICANCE OF THE TIME-DEPENDENT NUCLIOE ADJOINT

It is well known that the solution to the adioint time-dependent Boltzmann transport equation can be interpreteu as follows:

$$
\begin{aligned}
\phi^{\star}(t)= & \text { "importance of a neutron at time } t \text { to the response } \\
& \text { at time, } t \text { " } 9 \text { (Note - again, all phase space } \\
& \text { variables except "time" are inplicitly treated.) }
\end{aligned}
$$

Therefore, it is not surprising that a time-depeirent nuclide adjoint plays a similar role for final-time functionals in burn-up calculations. ise assert the following axion:

$$
\begin{aligned}
& N_{i} *(t)= \\
& \text { at timportance of nuclide } i \text { at time } t \text { to the response }
\end{aligned}
$$

For the particular case of the response being some final-time nuclide density, this definition can be stated more quantitatively by

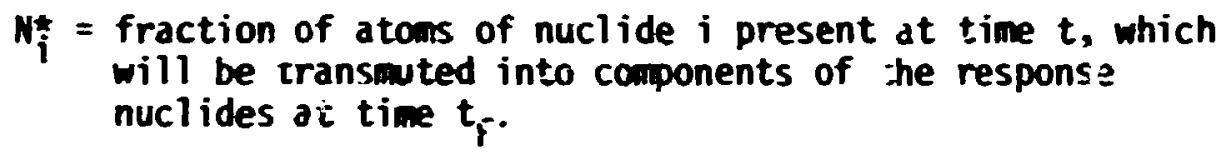

For the burn-up equation with a fixed neutron flux -ield, the above defiritions show that the adjoint nuclide field is independent of the forward field, and, therefore, a particular adjoint calculation is applicable to 31 ! reactor configurations wich have the same flux field as used in the original calcu!ation. This fact is analogous to the situation for the reutron adjoint, wich is applicable to all neutron fiux fields that have a coman nuclide field. In both instances the fonwart field is fixed by the initial condsions, and the adjcint field is fixed by the final response.

The imporiance property of the nuclide adjoirit can be used to directly derive the adjuint transmutation equation from first principles, in a manner similar to the method used by lewias to derive the neutron adjuint equation.9 The derivation is based on the principle for "conservation of nuclide importancr," which states that a nuclide in an 
specified neutron environment is as important as its daughters (from both reactions and decays). Fron this axium, it is easily seen that the importance of nuclide $i$ at time $t$ is equal to its importance at $t+\Delta t$ plus the importance of all daughters it produces during $\Delta t$. Let $\alpha_{i}$ be the total transmutation probability per unit time for nuclide $i$; then $\left(1-a_{i} \Delta t\right)=$ probability that nuclide $i$ does not transmute during $\Delta t$. Let $a_{i \rightarrow j}$ be the probability per urit time that nuclide $i$ will transmute into nuclide $j$. Then applying the conservation of nuclide importance:

$$
N_{i}^{\star}(t)=N_{i}^{\star}(t+\Delta t)\left(1-a_{i} \Delta t\right)+\sum_{j \neq i} c_{i+j} N_{j}^{*} \Delta t,
$$

rearranging terms,

$$
\left.\frac{N_{i}^{\star}(t)-N_{i}^{\star}(t+\Delta t)}{\Delta t}=-a_{i} N_{i}^{\star \prime} \cdot t+\Delta t\right)+\sum_{j \neq i} a_{i \rightarrow j} N_{j}^{\star} .
$$

Finally, taking the limit $\Delta t \rightarrow 0$,

$$
\sum_{j} a_{i+j} N_{j}^{*}=-\frac{d}{d t} N_{i}^{*},
$$

where $a_{i j}$ is defined to $-a_{i}$. This equation can be written in vector notation as

$$
-\frac{d}{d t} \underline{N}^{\star}=\underline{\underline{A}} \underline{N}^{\star} \text {. }
$$

Comparins the elements of $A$ to the elements of the burn-up matrix $M$ (see Appendix $A$ ), we see that $\underline{\underline{A}}=$ transpose $\underline{\underline{M}}=M^{\star}$. Therefore $M^{*} N^{*}=$ $-\frac{d}{d t} N^{\star}$.

The importance conservation property of the adjoint-nuclide field also makes possible the creation of a "nuclide channel theory." The 
concept of neutron channel theory has been introduced in an earlier paper as a method to determine the mechanism by which neutrons flow from the forward source to the response detector, so as to locate spatial streaming paths. ${ }^{18,19}$ A similar idea can be applied to the nuclide field to find the major "nuclide paths" by wich atoms are transformed from the initial isotopic concentrations into the firal response concentrations.

io this end, a quantity known as the "nuclide contributon density" can be defined to be:

$$
\begin{aligned}
c_{i}(t)= & \text { number of atoms of nuclide } i \text {, per } \mathrm{cm}^{3} \text {, present } \\
& \text { at time } t \text { which become response atoms at time } t_{F} .
\end{aligned}
$$

It is easy to see from the definition of the adjoirt,

$$
c_{i}(t)=N_{i}(t) N_{i}^{\star}(t) .
$$

Because the final response must originate from some nuclide present in the system,

$$
\sum_{i} c_{i}(t)=\text { final response }
$$

for all $t$ in the interval $\left[t_{j}, t_{f}\right]$, which can be written as

$$
\underline{N}^{\top}(t) \underline{N}^{\star}(t)=\text { constant }=\underline{\underline{h}}^{\top} \underline{N}\left(t_{f}\right)=\text { response. }
$$

A knowledge of $c_{j}(t)$ for all nuclides allows one to determine which isotopes at time $t$ contribute must heavily to the response of interest. This property could possibly be bencficial to optimization studies in reactor design. 


\section{TIME-DEPENDENT UHCERTAINTY ARALYSIS}

Time-dependent uncertainty analysis is similar to the static uncertainty theory previously developed, and some of the following derivations are based on earlier works. The established approach is to use the results of Section II to define "sensitivity coefficients" wich can be used in conjunction with covariance files for basic nuclear data to develop uncertainties in responses of interest. For the present study, the sensitivity coefficients are defined with time-dependent vectors, compared with energy functions for the static case.

The existing evaluations of nuclear data can be thought of as representing the mean value (albeit weighted) derived from a distribution of microscopic measurements. With the issue of ENOF/B-IV - and greatly extending into ENDF- $Y$ - the second moments of the distribution of measurements (i.e., the variances and covariances) representing correlated uncertainties are specified to provide the analyst with a measure of the quality of the data.20,21

To briefly demonstrate how sensitivity theory is combined with data uncertainty files, let us consider a reference data collection (assumed to be the mean value of several measurements) that will again be designated as the "data vector" $\underline{S}\left(a_{i}\right)$. As before, the elemer.ts $a_{j}$ of $\underline{S}$ represent the decay data, microscopic reaction rates $(\sigma \phi)$, etc., that are to be used in some depletion calculations. With this collection of data, the expectation value of ihe response is calculated to be $R(\underline{S})$.

If some other data vector $\underline{S}_{n}$ were used in the calculation, then another value for the response would be obtained, $R_{n}\left(S_{n}\right)$. The distribution of all such possible calculated responses, due to the distribution of nuclear data, is described by the response variance, given by

$$
v=\frac{1}{N} \sum_{n=1}^{N}\left(R_{n}-R\right)^{2},
$$

with $N=$ number of data vectors used in computing the mean set $s$; i.e., $N$ is related to the nuiber of measurements for the a's in $\underline{s}$.

Expanding $R_{n}$ in a first-order Taylor series about the expectation value gives 


$$
R_{n}=R+\frac{\partial R(S)^{\top}}{\partial \underline{S}}\left(\underline{S}_{n}-\underline{S}\right)
$$

where the vector derivative $\frac{\partial}{\partial \underline{S}}$ is defined to be the colum vector operator with components $\frac{\partial}{\partial a_{i}}$.

Substituting Eq. (55) into Eq. (54) results in

$$
v=\frac{1}{N} \sum_{n}\left(\frac{\partial R}{\partial \underline{S}} \Delta \Delta_{-n}\right)^{2}
$$

Now defining a diagonal matrix of the form

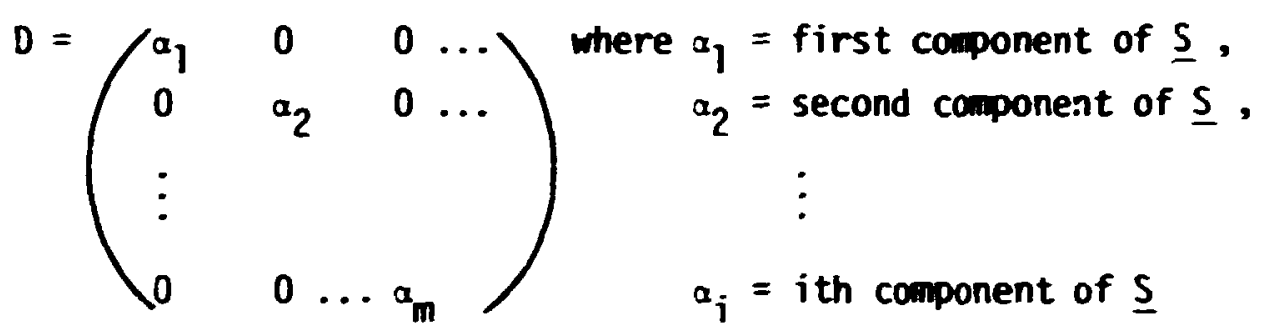

Equation (56) can be written

$$
\begin{aligned}
& l^{\prime}=\frac{1}{N} \sum_{n}\left\{\frac{\partial R}{\partial \underline{S}}\left(\underline{\underline{D}} \frac{1}{\underline{D}}\right) \Delta_{n}\right\}^{2}
\end{aligned}
$$

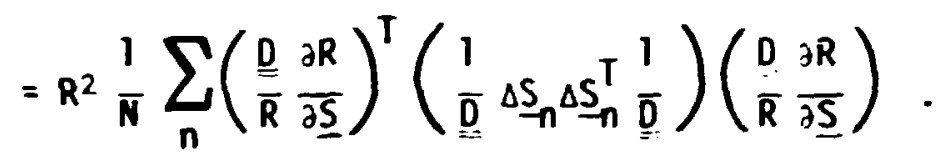

Noting that $\frac{\partial R}{\partial \underline{S}}$ is independent of the summation index, Eq. (57) is finaliy expressed as

$$
\frac{v}{R^{2}}=\underline{P} \underline{T} \underline{P}=\text { :elative response variance. }
$$


where

$$
\begin{aligned}
& \underline{P}=\frac{\underline{D}}{\bar{R}} \frac{\partial R}{\partial \underline{S}} \\
& \underline{\underline{C}}=\frac{1}{N} \sum_{n}\left(\frac{1}{\bar{D}} \Delta \underline{S}_{n} \Delta \Delta_{n}^{T} \frac{1}{D}\right)
\end{aligned}
$$

The ratrix $\underline{C}$ formed by the dyadic square of $\Delta \underline{S}_{n}$ is called the "relative covariance mitrix," and the vector $\underline{P}$ is called the "sensitivity vector." Let us consider one component of $\underline{P}$ :

$$
f_{i}=\frac{\alpha_{i}}{R} \frac{\partial R}{\partial \alpha_{i}}=\frac{\partial R / R}{\partial \alpha_{i} / \alpha_{i}}
$$

Equation (8) can be used to evaluate the partial derivative accurate through first order:

$$
\frac{\partial R}{\partial \alpha_{i}}=\left\langle\underline{N}^{\star T} \frac{\partial}{\partial \alpha_{i}} \underline{M} \underline{N}\right\rangle
$$

If we assume as an example that the data $\alpha_{j}$ appears only in position $(k, l)$ of the burn-up matrix, then $\frac{\partial}{\partial \alpha_{i}} \underline{M}$ is a matrix with zeros in all positions excapt $(i, l)$, where its value is $\frac{\partial}{\partial \alpha_{i}}\left(m_{k \ell}\right)$. Therefore in
general

$$
P_{i}=\frac{a_{i}}{R} \sum_{k, l}\left\langle\left[N_{h}(t) \frac{\partial m_{k \ell}}{\partial \alpha_{i}} N_{\ell}(t)\right]\right\rangle
$$

Thus we see that uncertainty analysis involves both a knowiedge of the data covariances and the sensitivity vector. We will now consider a sample problem to illustrate the procedure for determinirg the sensitivity vector; ayestions concerning the covariance riatrix wi?l not be addressed. 


\section{PROEIEM SPECIFICATION}

Time-dependent sensitivity theory was applied to the analysis of a thermal reactor depletion calculation that was specified by the Electric Power Research Insitute (EPRI). ${ }^{22}$ A point-model of the homogenized fue? zone was used in the sensitivity calculation, with the initial concentrations listed in Table 1. The time dependent $t^{t}$. wal flux (Table 2) was obtained from an earlier non-linear burn-up calculation supplied by EPRI.

Point depletion calculatiors for the forward and adjoint nuclide fields were performed with the computer code ORIGEN-A, a modified version of ORIGEN (described in detail in Appendix $A$ ). ORIGEY solves a zero dimerisional version of the burn-up equations using the matrix exponential technique, a method which allows a wide variety of nuclides to be included in the depletion calculation. Nuclear data was obtained directly from the ORIGEN PWR libraryl2 (three cross section groups) for computational convenience.

The calculated response was the total plutonium inventory $(239,240,241,242 \mathrm{Pu})$ at end of cycle $\left(t_{f}=25614\right.$ hours $)$. The standard deviation in this response was estimated using approximate standard deviations for the $238 \mathrm{U}$ capture and $239 \mathrm{Pu}$ fission cross sections.

Uncertainties in these cross sections are the two major causes for uncertainty in the $\mathrm{Pu}$ producticn. Most other pertinent data have either low sensitivity coefficients or sirall uncertainties (as for decay constants); therefore consideration only of the $238 \mathrm{U}$ and $239 \mathrm{Pu}$ cross sections can provide a reasonable lower bound for the total standard deviation of the plutonium inventory at end of cjcle.

\section{RESULTS}

The values for the most important time-dependent actinide densities found in the forward ORIGEN-A calculation are showr ir. Figs. 1 and 2. As expected, the concentrations of uranium and piutonium isotopes cominate the res,ults of the forward use, with $238 \mathrm{U}$ being the most predominate by far, due to its large iritial concentration. Figure 3 shows the major chains for plutonium build.up. 
Table 1. Initial concentrations for homogenized fuel

\begin{tabular}{ll}
\hline Nuclide & Number density \\
\hline 160 & $4.37-02$ \\
$135 \mathrm{X}$ & 0.0 \\
$149 \mathrm{Sm}$ & 0.0 \\
$234 \mathrm{U}$ & $4.45-06$ \\
$235 \mathrm{U}$ & $5.67-04$ \\
$236 \mathrm{U}$ & $3.53-66$ \\
$238 \mathrm{U}$ & $2.13-02$ \\
$239 \mathrm{Pu}$ & 0.0 \\
$240 \mathrm{Pu}$ & 0.0 \\
$241 \mathrm{Pu}$ & 0.0 \\
$242 \mathrm{Pu}$ & 0.0 \\
$241 \mathrm{Am}$ & 0.0 \\
\hline
\end{tabular}


Table 2. Time-dependent thermal flux

\begin{tabular}{crc}
\hline Time interval & \multicolumn{1}{c}{$t_{i}(\mathrm{hr})$} & $\begin{array}{c}0\left(\times 10^{13}\right) \\
\text { neutrons } / \mathrm{cm}^{2} \cdot \mathrm{sec}\end{array}$ \\
\hline 1 & 75.34 & 4.52 \\
2 & 376.68 & 4.54 \\
3 & 1506.68 & $4.5^{2}$ \\
4 & 3013.42 & 4.43 \\
6 & 4520.13 & 4.38 \\
7 & 6026.84 & 4.37 \\
8 & 7533.55 & 4.38 \\
9 & 9040.26 & 4.41 \\
10 & 10546.97 & 4.46 \\
11 & 12053.68 & 4.51 \\
12 & 13560.39 & 4.58 \\
13 & 15067.10 & 4.65 \\
14 & 16573.81 & 4.72 \\
15 & 18080.52 & 4.81 \\
10 & 19587.13 & 4.89 \\
17 & 21093.94 & 4.98 \\
18 & 22600.65 & 5.07 \\
19 & 24107.36 & 5.17 \\
\hline
\end{tabular}




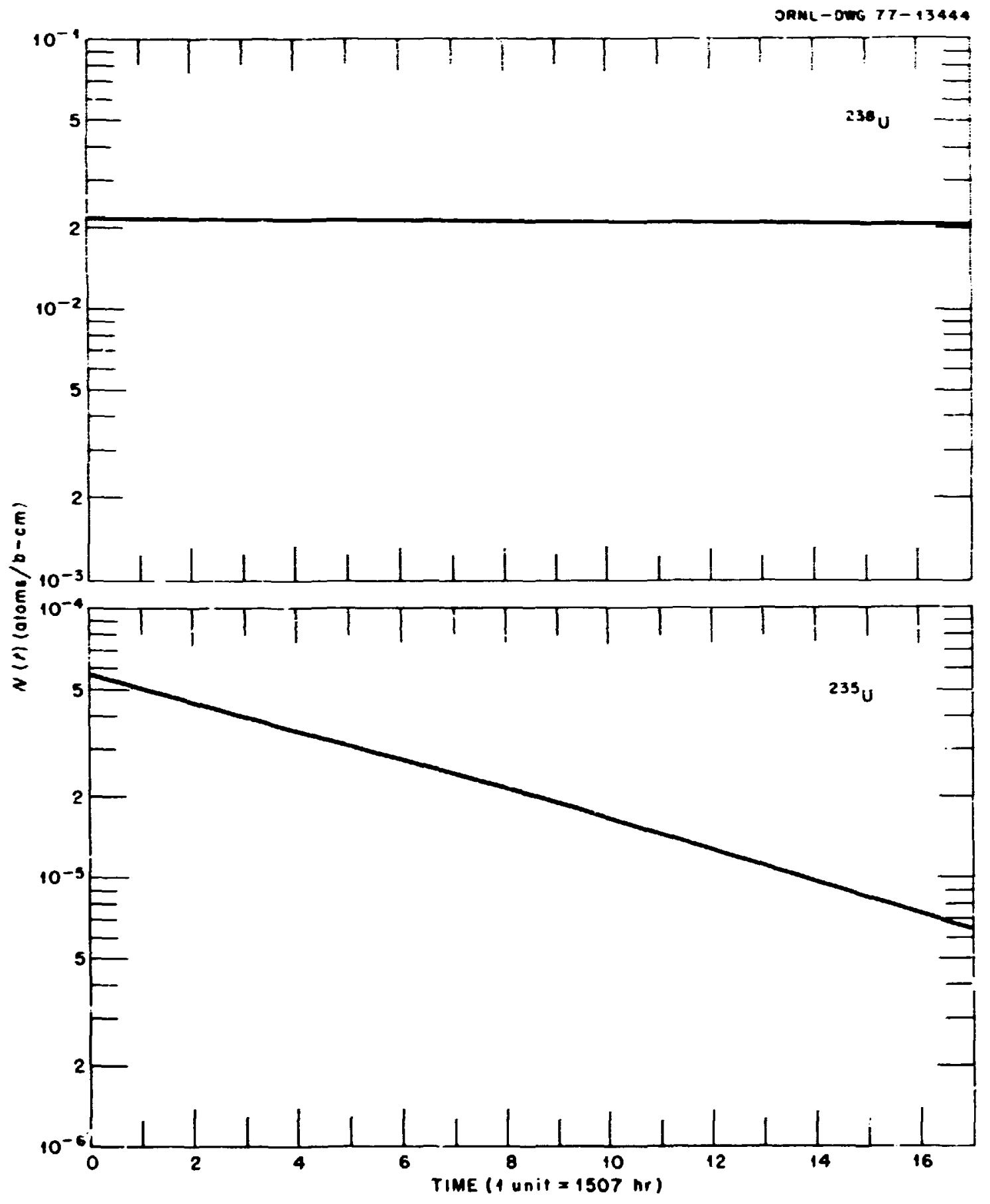

Fig. 1. Uranium atom densities. 




Fig. 2. Plutonium atom densities. 


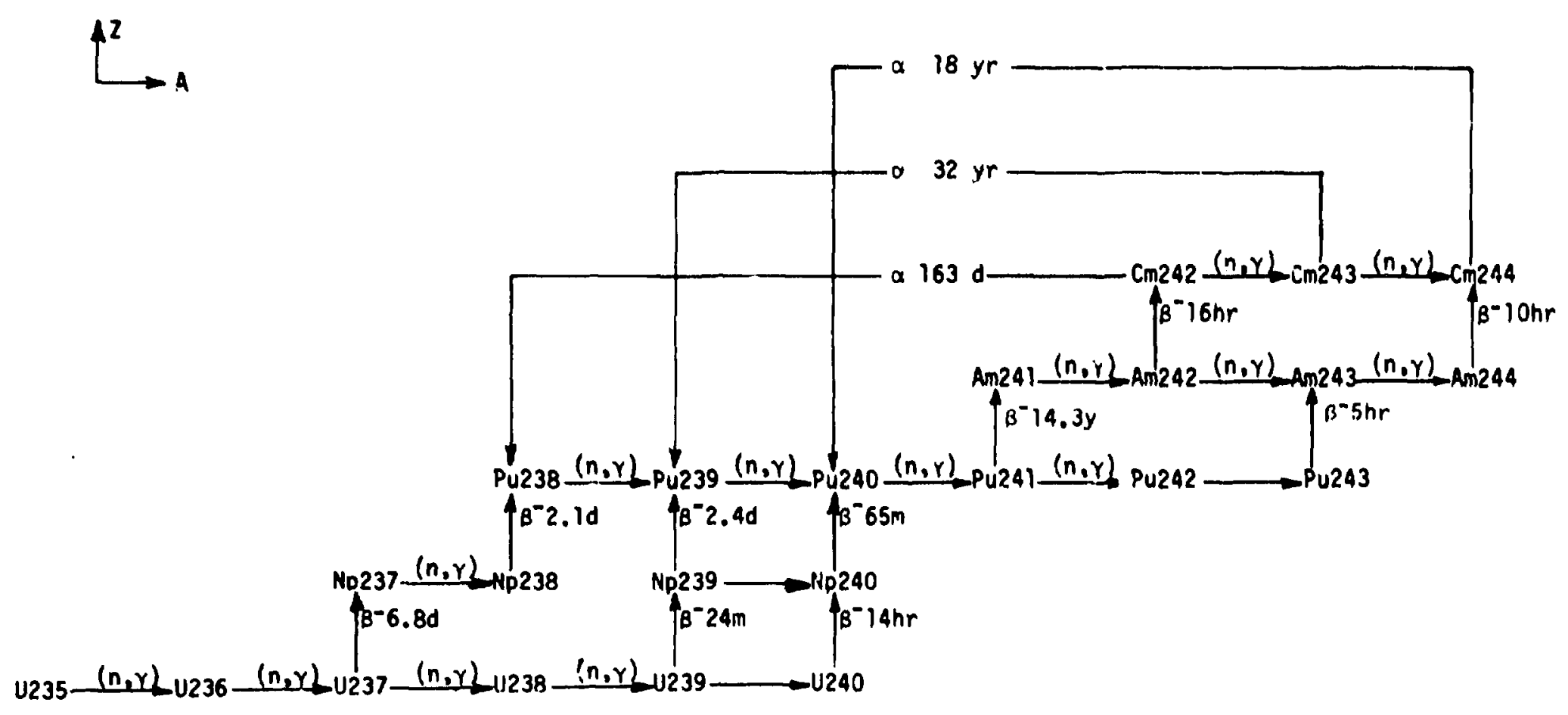

Fig. 3. Major chains for plutonium production 
Figures 4-8 sumarize the results of the adjoint ORIGEN-A calculation. For this run the "initial" (actually, final) $(a)$ valjes were zero for all nuclides except $239 \mathrm{Pu}, 240 \mathrm{Pu}, 241 \mathrm{Pu}$, and $242 \mathrm{Pu}$, wich had concentrations of 1.0 , since this is the realization vector rorresponding to a response of "plutonium inventory at shutdown." The flux in Eq. (27) was onitted because reaction rates are not being considered.

At first sight it may be surprising to see some of the more uncour.on isotczes (such as ${ }^{237} \mathrm{U},{ }^{242} \mathrm{Cm}$, etc.) appearing among the important isotopes for producing plutonium. It may be equally surprising that the dominant nuclide is the forward calculation - $238_{U}$ - is not anong the most dominant adjoint values. The results appear more reasonable when one realizes that the "importarce" of a nuclide is independent of its concentration. Even though nuclides such as $240 \mathrm{~Np}$ have only a small number of atoms present at any given time, any atom which is present has a high probability of being transformed into a plutonium atom by shutdown. The importarce of $238 \mathrm{U}$ atoms $\left(\sim 10^{-3}\right)$ is comparatively low due to its having a smiller capture cross section $(b)(\sim 3 b)$ than more important isotopes, such as ${ }^{237} \mathrm{~Np}(\sim 170 \mathrm{~b})$. Therefore a ${ }^{238} \mathrm{U}$ atom has less probability of being transformed into Pu than does a ${ }^{237} \mathrm{~Np}$ atom; i.e., a smaller fraction of $238 \mathrm{U}$ will transmute into $\mathrm{Pu}$, al though the absolute number of $238 \mathrm{U}$ atoms which contribute to the response is much greater than for ${ }^{237} \mathrm{~Np}$, since there are far more ${ }^{238} \mathrm{U}$ atoms than $\mathrm{Np}$ atoms present in the reactor.

An examination of several nuclide adjoints will perhaps give the reauer a better physical insight. The $\mathrm{Pu}$ response isotopes themselves are obviously important, especially at times near $t_{f}$. At earlier times, the high fission cross section makes an atom of a fissile $\mathrm{Pu}$ isotope quite like'y to disappear before it lives to $t_{f}$. The adjoint for $238 \mathrm{pu}$ decreases riear $t_{f}$ because it was not directly contained in the response.

(a) See Appendix A, for inverted solution to the adjoint equation.

${ }^{(b)}$ Cross sections quoted are $2200 \mathrm{~m} / \mathrm{s}$ values. 


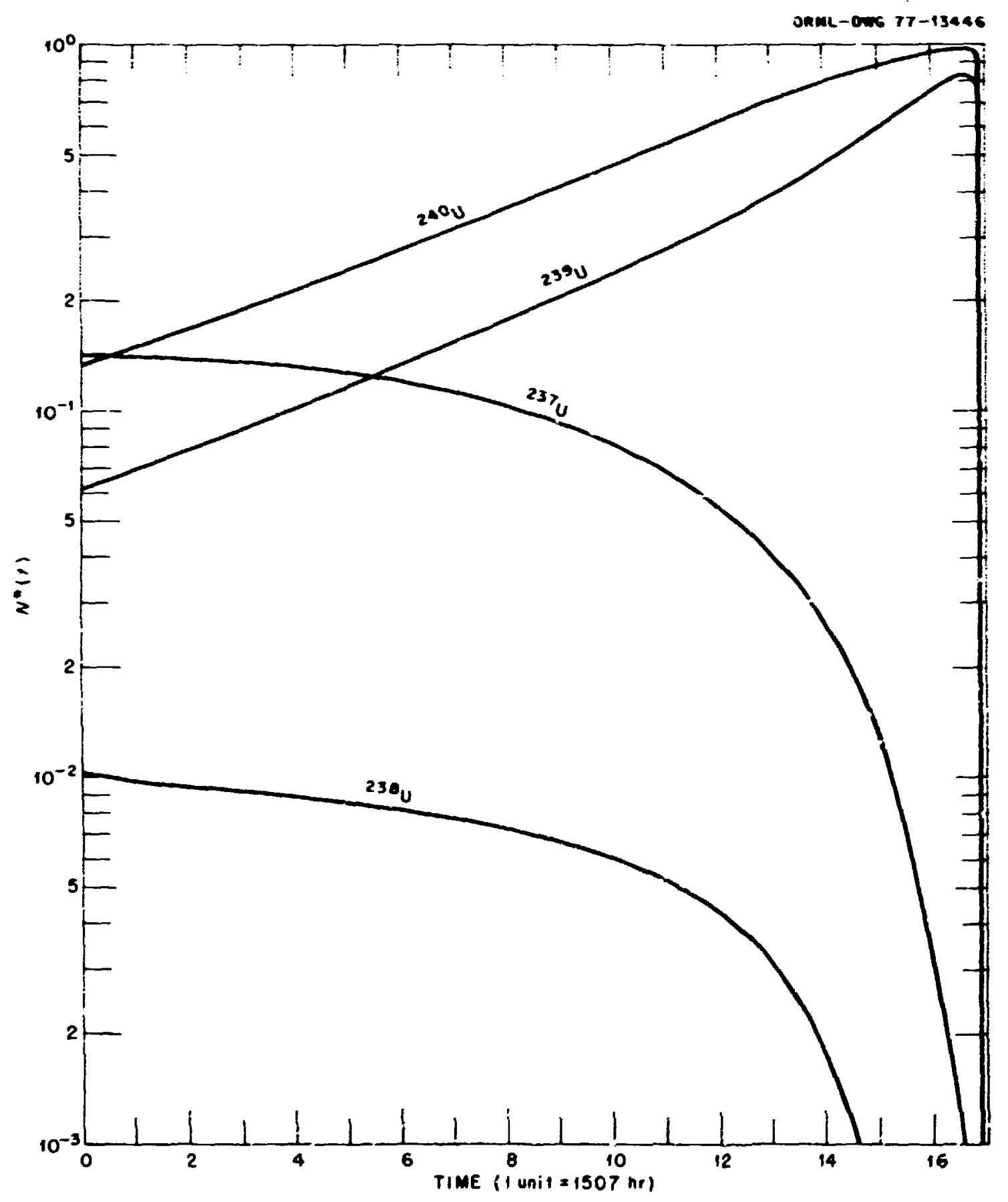

Fig. 4. Uranium adjoint functions. 


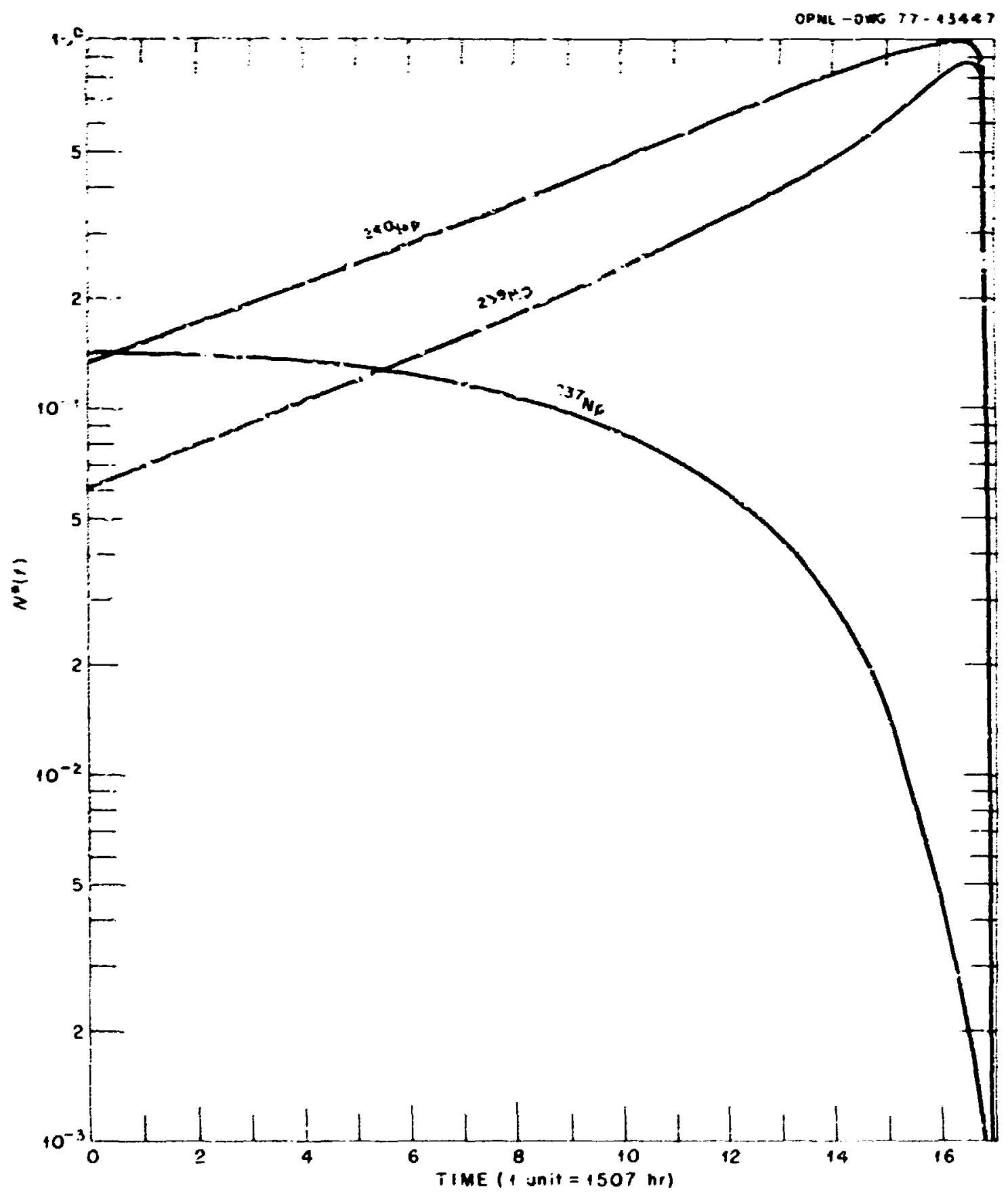

Fig. 5. Neptunium adjoint functions. 
30

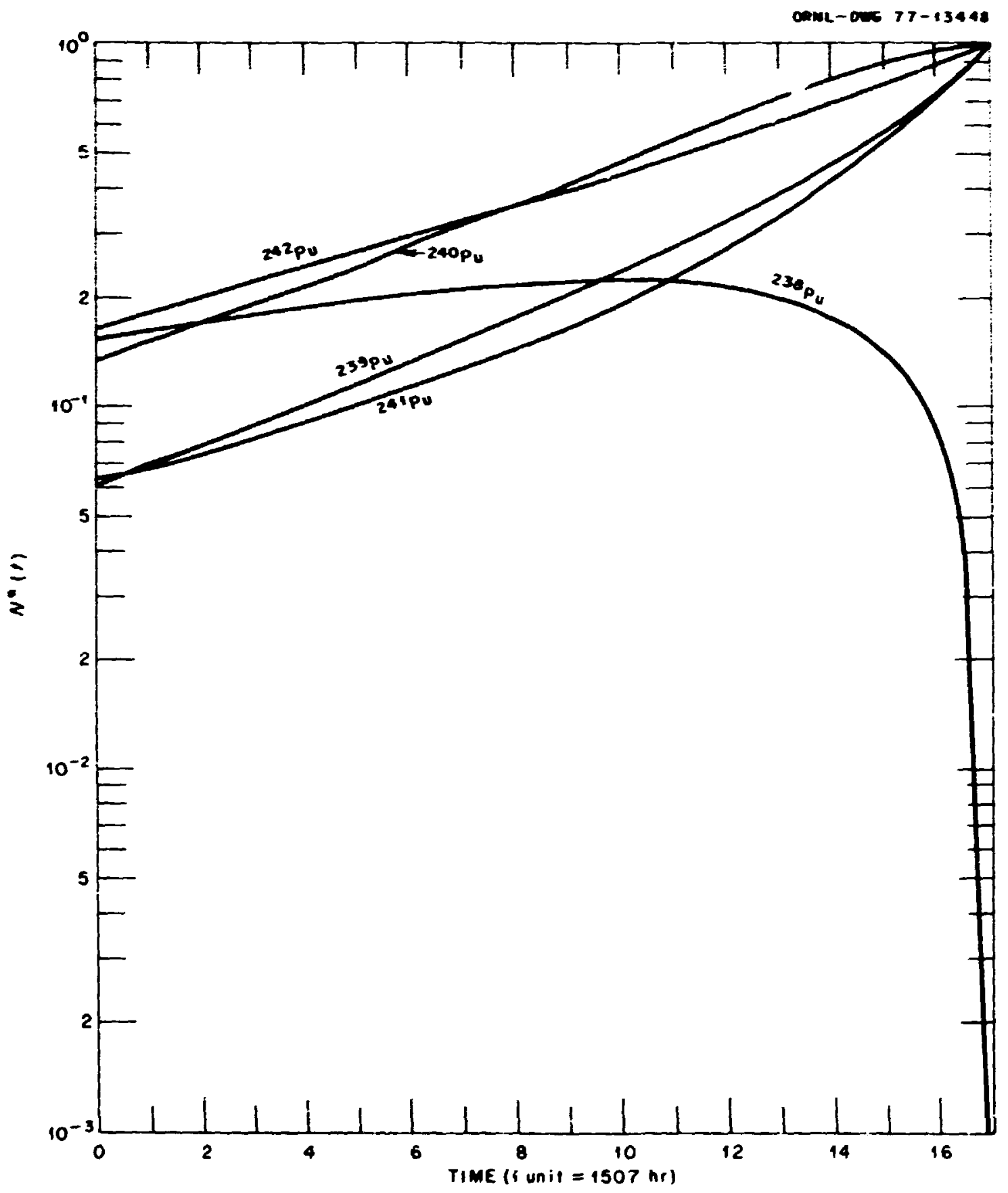

Fig. 6. Plutonium adjoint functions. 


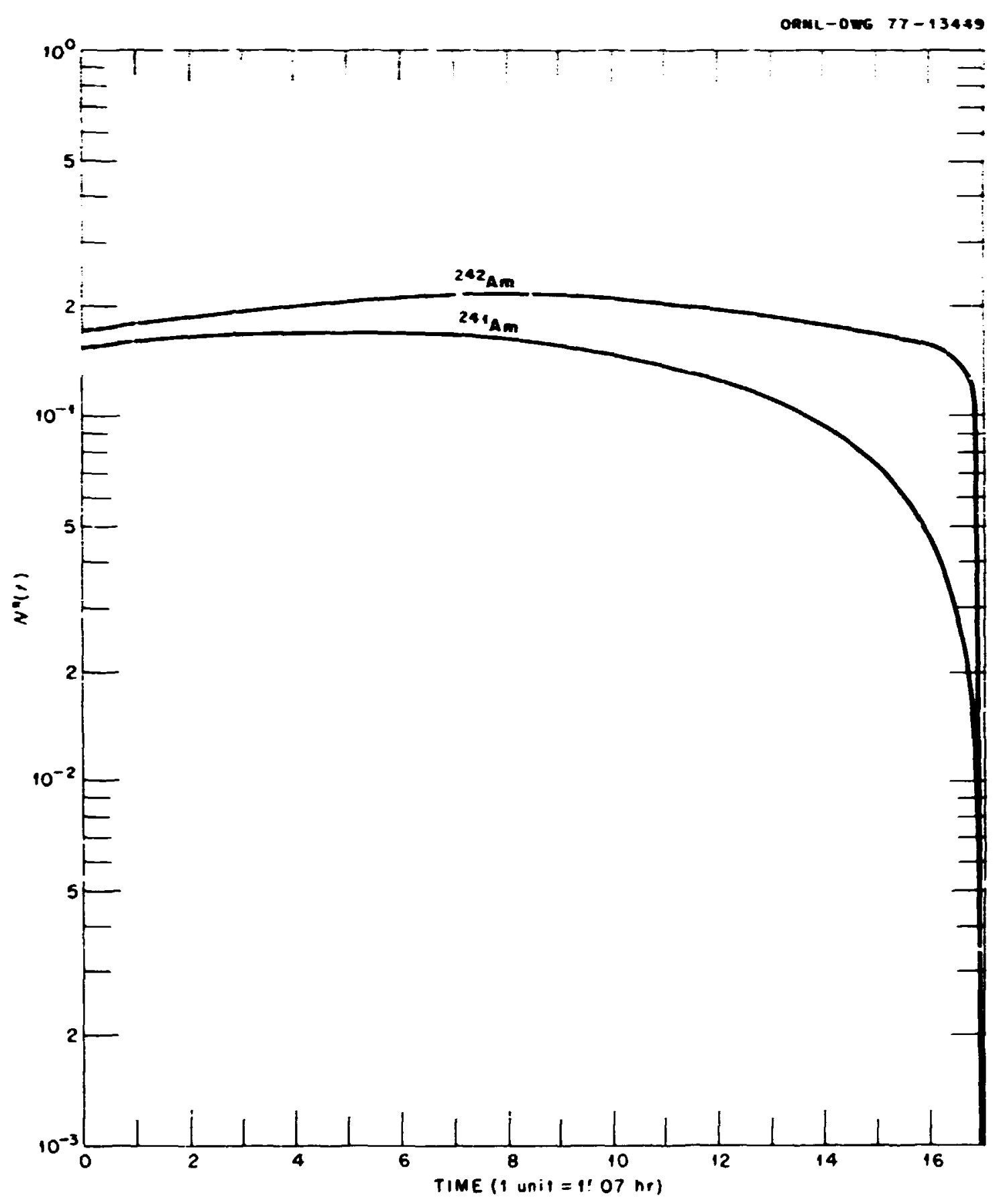

Fig. 7. Americium adjoint functions. 


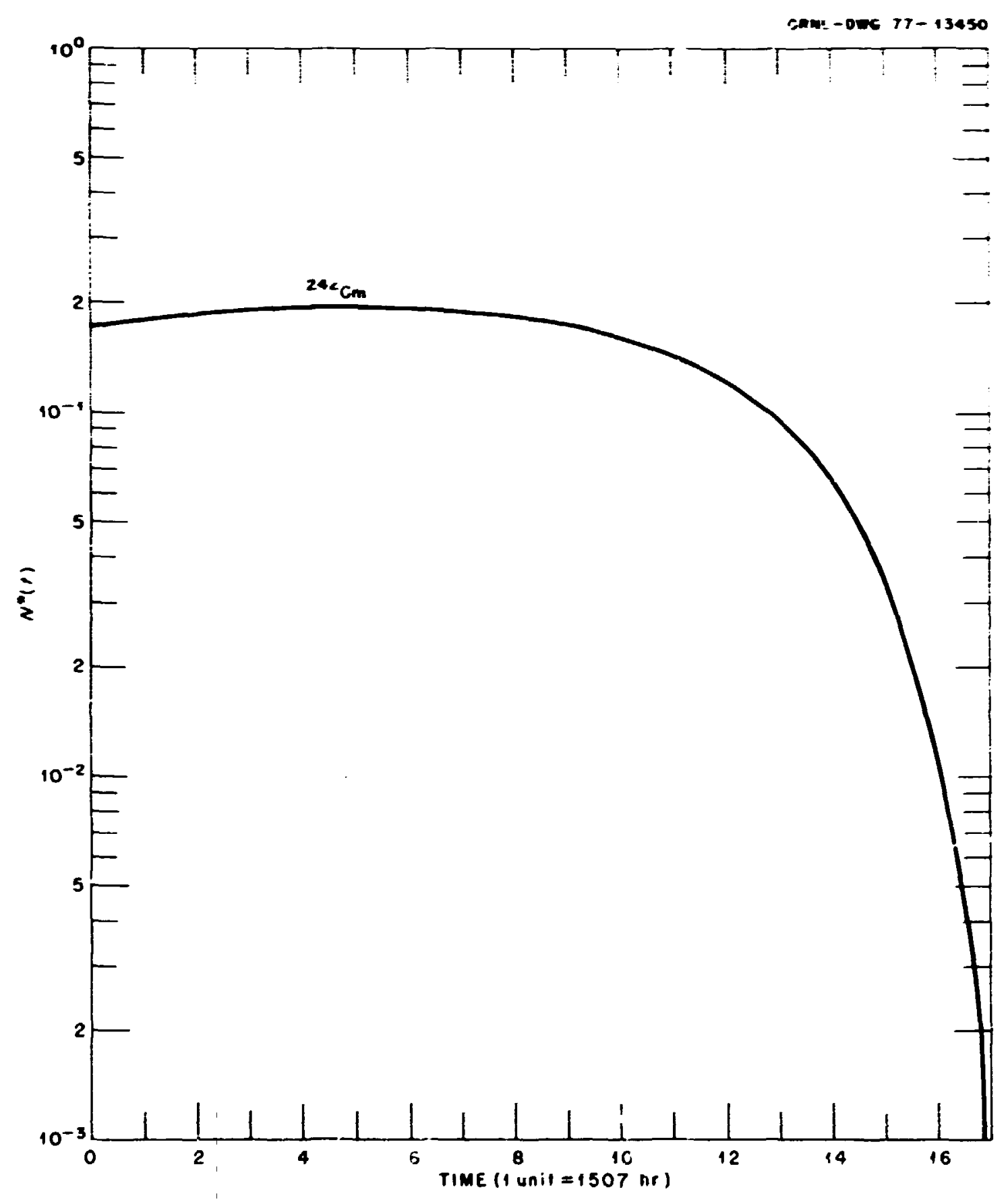

Fig. 8. Curium adjoint function. 
Actinides with a higher atoric numer thar 94 arz usually important tinrough their decay modes. For example, $=C_{m}$ has a moderate absorption cross section ( $30 \mathrm{~b}$ ) and a relatively short ha: $4-1$ ife $(163 \mathrm{~d})$; therefore it has about thirty times greater probability of cecaying to - ${ }^{\mathbf{C}} \mathrm{PL}$ before it captures a reutron to becone :- $C_{n:}$ - note the similarity in the : ipu adjoint curve ard the :-Cm, adjoint curve. Furthermore, even if the $\therefore i \mathrm{in}$ aton does transmute to $-\mathrm{Cm}$, there is still a possibility that the $2+i \mathrm{Con}$ isotope will decay to : : $\mathrm{Pu}$.

Americiun-242 is important because it decays by beta enission to $\therefore-\mathrm{Cm}$ and iy electrcn capture directly tc :-P Pu, and its short half-life $i t_{i}:=16$ hours) makes the transition $i:$ ely over a long time period. In fact, even at one time interval before shutdown its adjoint is still quite high. At early times the isotope $\because U$ is an important ni-lide whose mode of contribution ir fairly complicated to assess. Its short half-life (7 days) and large capture cross section (48C b) provide two possible methods for the nuclide to transmute into $\mathrm{Pu}$. If : U captures a neutron, it becomes: $3 \mathrm{U}$ and follows the familiar procedure for creating $23 \mathrm{Pu}$. The alternate method is for $: 3^{7} \mathrm{U}$ to decay by beta emission to: ${ }^{7} \mathrm{~Np}$. Since this nuciide has a long half-life $\left(2 \times 10^{\circ} \mathrm{y}\right)$, it is probabia that an atom will capture a neutron $\left(r_{c}=169\right)$ and become $2{ }^{38} \mathrm{~Np}$, which then decays $\left(t_{1 / 2}=2.12\right.$ days $)$ into $23.9 \mathrm{Pu}$. An examination of Figs. 3 and 4 reveals that over most of the cycle, $: 37 \mathrm{U}$ is more impor sant than $239 \mathrm{U}$, but slightly less important than : $\mathrm{Np}$, a fact which leads one to believe that the second contribution mode is more important.

Table 3 (see Eq. 51) contains the values of the contributon densities for the major nuclides. It is seen that until near the end of cycle the response stored in the $30 \mathrm{U}$ atoms overwhelms all others, due to its large initial charge. At time step 17, Pu begins to dominate, as the $238 \mathrm{U}$ atoms are "running out of time" in whic', they can trarsmute into Pu. Notice the initial contributon density for $39 \mathrm{U}$ is $2.15 \times 10^{-i,}$, which was found to be exactly the value of the plutonium inventory at shutdown (see last row in Table 3). This indicates - as expected - that initially the entire response is contained in the $2391 \mathrm{~J}$ atoms:

$$
R\left(t_{f}\right)=\left(N_{0} N \hbar\right)_{2 j 9} U
$$


Table 3. Major contributon densities (atoms $/ \mathrm{cm}^{3} \times 10^{-26}$ )

\begin{tabular}{clllll}
\hline $\begin{array}{c}\text { Time } \\
\text { interval }\end{array}$ & $238 \mathrm{U}$ & $239 \mathrm{Pu}$ & $240 \mathrm{Pu}^{241 \mathrm{Pu}}$ & $242 \mathrm{Pu}$ \\
\hline 1 & $2.15-4$ & 0 & 0 & 0 & 0 \\
2 & $2.15-4$ & 0 & 0 & 0 & 0 \\
3 & $2.15-4$ & 0 & 0 & 0 & 0 \\
4 & $2.13-4$ & $2.36-6$ & 0 & 0 & 0 \\
5 & $2.09-4$ & $4.63-6$ & $1.08-6$ & 0 & 0 \\
6 & $2.06-4$ & $6.80-6$ & $2.27-6$ & 0 & 0 \\
7 & $2.01-4$ & $8.94-6$ & $3.82-6$ & 0 & 0 \\
8 & $1.97-4$ & $1.12-5$ & $5.71-6$ & 0 & 0 \\
9 & $1.91-4$ & $1.36-5$ & $7.92-6$ & $1.04-6$ & 0 \\
10 & $1.86-4$ & $1.63-5$ & $1.05-5$ & $1.54-6$ & 0 \\
11 & $1.78-4$ & $1.91-5$ & $1.35-5$ & $2.13-6$ & $1.18-6$ \\
12 & $1.70-4$ & $2.24-5$ & $1.70-5$ & $2.89-6$ & $1.76-6$ \\
13 & $1.60-4$ & $2.63-5$ & $2.09-5$ & 3.825 & $2.53-6$ \\
14 & $1.49-4$ & $3.11-5$ & $2.53-5$ & $5.02-6$ & $3.50-6$ \\
15 & $1.35-4$ & $3.71-5$ & $3.03-5$ & $6.57-6$ & $4.73-6$ \\
16 & $1.19-4$ & $4.43-5$ & $3.58-5$ & $3.65-6$ & $6.22-6$ \\
17 & $9.81-5$ & $5.39-5$ & $4.15-5$ & $1.15-5$ & $8.10-6$ \\
18 & $7.29-5$ & $6.70-5$ & $4.73-5$ & $1.55-5$ & $1.03-5$ \\
19 & $4.04-5$ & $8.58-5$ & $5.22-5$ & $2.15-5$ & $1.30-5$ \\
20 & 0 & $1.14-4$ & $5.48-5$ & $3.02-5$ & $1.62-5$ \\
\hline
\end{tabular}


Table 4. Time-dependent sensitivity profile for $\mathrm{Pu}$ inventory at shutdown

\begin{tabular}{ccc}
\hline Time interval & $238 \mathrm{U}(\mathrm{n}, \mathrm{\gamma})$ & $239 \mathrm{Pu}(\mathrm{n}, \mathrm{f})$ \\
\hline 1 & $5.24-4$ & 0 \\
2 & $2.13-3$ & 0 \\
3 & $8.58-3$ & $-1.06-3$ \\
4 & $1.29-2$ & $-4.16-3$ \\
5 & $1.48-2$ & $-6.71-3$ \\
6 & $1.70-2$ & $-9.23-3$ \\
7 & $1.97-2$ & $-1.19-2$ \\
8 & $2.31-2$ & $-1.47-2$ \\
9 & $2.69-2$ & $-1.79-2$ \\
10 & $3.15-2$ & $-2.14-2$ \\
11 & $3.72-2$ & $-2.55-2$ \\
12 & $4.39-2$ & $-3.04-2$ \\
13 & $5.24-2$ & $-3.64-2$ \\
14 & $6.29-2$ & $-4.39-2$ \\
15 & $7.65-2$ & $-5.34-2$ \\
16 & $4.35-2$ & $-6.56-2$ \\
17 & $1.20-1$ & $-8.23-2$ \\
18 & $1.53-1$ & $-1.06-1$ \\
19 & $8.70-2$ & $-1.41-1$ \\
Total & 0.835 & -0.671 \\
\hline
\end{tabular}


The differential time-dependent sensitivity profiles for ${ }^{238} \mathrm{U}$ capture and ${ }^{239} \mathrm{Pu}$ fission are given in Table 4 . Because the capture cross section appears as both a loss and a gain (a negative effect due to burn-ip of a fertile isotope; a positive eifect cue to production of ${ }^{239} \mathrm{Pu}$ ), errors in this value tend to cancel somewhat in the determination of the response uncertainty. The uncertainty for ${ }^{239} \mathrm{Pu}$ fission cross section impacts the response directly since it is a loss mechanism for the response nuclide of interest.

Detailed covariance files for the thermal energy range are only now being developed, and were not available for the present work. Estimated standard deviations of $3 \%$ for both the ${ }^{238} \mathrm{U}$ capture and the ${ }^{239} \mathrm{Pu}$ fission cross sections were used in this study. These values were obtained by assuming cross section uncertainties of $i \%$ in the thermal range and $5 \%$ in the epithermal range, with 3:1 weighting function over these ranges, respectively. 23,24 Based on these approximate uncertainty estimates, the associated relative standard deviation in plitonium f roduction is found to be $23 \%$, arising from ${ }^{238} \mathrm{U}$ capture uncertainty; and $22 \%$ arising from $239 \mathrm{Pu}$ fission uncertainty. This results in a relative standard deviation of approximately $3 \%$ in plutonium inventory at shutdown.

It is important to note that the value for the standard deviation does not reflect uncertainties in half-lives, branching ratios, or reaction cross sections in nuc!ides other than $238 \mathrm{U}$ and $239 \mathrm{Pu}$; nor does it contain any cross correlation between ${ }^{238} \mathrm{U}$ and $239 \mathrm{Pu}$ data. The calculated value is only intended as a lower bound for the response uncertainty. More accurate results will be obtained after more complete error files are made available on the ENDF-5 data evaluation, soon to be released.

\section{SUMMARY AND CONCLUSIONS}

Sensitivity and uncertainty analysis for functionals of the timedependent nuclide density field has been implemented into the present ORNL sensitivity program using methods that are similar to thcse developed for the static case. The computer code ORIGEN-A (see Appendix B) 
has extended the capability of the ORIGEN burn-up code to aliow calculation of nuclide adjoint functions for final-time, linear functionals and functional ratios, as well as the normal forward calculation. When the forward and adjoint values are coupled, sensitivity coefficients can be computed for all nuclear data contained in the burn-up matrix (e.g., microscopic cross sections, decay constants, yields, branching ratios, etc.). The sensitivity coefficients relate changes in response to changes in nuclear data.

The concept of "nuclide importance" has been quantified and compared to its predecessor "neutron importance." This allowed for the development of a "nuclide channel theory," which indicates the isotope "channels" through which a nuclide field is transformed from its initial configuration to some final response.

Uncertainty aralys is for nuclide density functionals was shown to be based on methods similar to those already in use in the FaRSS system. Extensions of existing programs are required with respect to achieving compatability with the ORIGEN-A output and accessing uncertainties in decay constants, yields, etc.

A sample calculation illustrated the generation of nuclide adjoints and their use in channel theory and in time-dependant sensitivity/ uncertainty analysis. For assumed standard deviations of $3 \%$ in $238 \mathrm{U}$ capture and ${ }^{239} \mathrm{Pu}$ absorption cross sections, the minimum uncertainty in the plutonium inventory after approximately three years of a PWR reactor operation was found to be near $3 \%$.

\section{ACKNOWLEDGMENTS}

The authors wish to thank 0 . W. Hermann and $C$. W. Kee for their assistance in fathoming the logic of the ORIGEN code to implement the programming for adjoint calculations. Appreciation is also extended to 0 . Ozer of the Electric Power Research Institute, who suggested the sample protilem and provided necessary depletion parameters. 


\section{APPENCIX A: NUMERICAL SOLUTION TO THE LINEARIZED ADJOINT BURN-UF ÉQUUATION}

The burn-up equation is a statement of mass balance for a radioactive nuclide field subjected to a neutron flux. The equation for nuciide species $i$ can be written:

$\frac{d N_{i}}{d t}=-\left(\sigma_{a i} \phi+\lambda_{i}\right) N_{i}+\sum_{j \neq i}\left(\sigma_{j \rightarrow i^{\phi}}+\lambda_{j \rightarrow i}\right) N_{j}$.

In matrix notation, the above equation is merely:

$$
\underline{M}\left(\alpha_{j \rightarrow i}\right) \underline{N}=\frac{\partial}{\partial t} \underline{N},
$$

$\alpha_{j \rightarrow i}=$ probability per unit time that isotope $i$ will be produced from isotope $j$, and $\alpha_{i j}=\underset{j}{-\Sigma} \alpha_{i \rightarrow j}$.

In Eq. (AI), the value for $\mathrm{N}$ can be found with the matrix exponential technique as

$$
\underline{N}(t)=\exp (\underline{M} t) \underline{N}_{0} \text {. }
$$

where $\exp (\underline{\underline{M}} \mathrm{t})$ is the time dependent matrix given by the infinite series

$$
\underline{I}+\underline{\underline{\underline{M}}} \mathrm{t}+\frac{\underline{\underline{\underline{M}}}^{2} \mathrm{t}^{2}}{2 !} \ldots \equiv \underline{\underline{B}(t)} .
$$

of course in reality the series is truncated at some finite number of terms dictated by the tolerance placed on $\underline{N}(t)$. The computer code ORIGEN solves the burn-up equations using this method, and a discussion of the numerical procedures involved in its implementation can be found in reference 12 . 
BLANK PAGE 
Note that the matrix $\underline{B}(t)$ is independent of the initial conditions $\underline{N}_{0}$; therefore, in theory it is possible to obtain a solution for a given $M(\phi)$ that does not depend on the initial reactor configuration. Then the time-dependent nuclide field is

$$
\underline{N}(t)=\underline{\underline{B}}(t) \underline{N}_{0} \quad \text { for any } \underline{N}_{0} \text {, }
$$

Unfortunately the nuclear data matrix $\underline{\underline{B}}$ is problem dependant (through the flux) and is too large ( 2800 by 800 words for each time step in CRIGEN) to be used efficiently. It is more advantageous to recalculate $\underline{N}\left(\tau\right.$ ) for each $\underline{N}_{0}$.

As previously discussed the adjoint burn-up equation is

$$
-\frac{d}{d t} \underline{N}^{\star}=\underline{\underline{M}}^{\top} \underline{N}^{\star} .
$$

Equation (A5) can be expressed in a form compatible with the present ORIGEN computational technique (i.e., a positive time derivative) by making a change of variable:

$$
\begin{aligned}
& t^{\prime}=t_{f}-t \\
& -\frac{d}{d t}=\frac{d}{d t^{\prime}} \\
& \underline{N}^{*}\left(t_{f}\right)=\underline{N}^{\star}\left(t^{-}=0\right)
\end{aligned}
$$

Then the adjoint solution is meroly

$$
\begin{aligned}
& \underline{N}^{*}\left(t^{-}\right)=\mathbb{N}^{\top} t^{-} \underline{N}^{\star}\left(t^{\prime}=0\right), \quad 0<t<t_{f} \\
& \underline{N}^{\star}(t)=\underline{N}^{*}\left(t_{f}-t^{\prime}\right), \\
& \underline{N}^{\star}\left(t_{f}\right)=\underline{N}^{\star}\left(t^{\prime}=0\right) \equiv \underline{N \neq}
\end{aligned}
$$


which is the same equation solved by the forward ORIGEN code, except the data matrix is transposed.

Equation (A7) can be written as

$$
\underline{N}^{\star}(t)=\exp \left[\underline{M}^{\top}\left(t_{f}-t\right)\right] \underline{N}_{f}^{*} \cdot
$$

It is easy to show that

$$
\exp \left(\underline{\underline{A}}^{\top}\right)=(\exp \underline{\underline{A}})^{\top},
$$

and therefore

$$
\underline{N}^{\star}(t)=\underline{\underline{B}}^{\top}\left(t_{f}-t\right) \underline{N}_{f}^{*}
$$

It is interesting to note that

$$
\begin{aligned}
& \underline{N}^{\top}(t) \underline{N}^{\star}(t)=\left[e^{\underline{M}} \underline{t}_{-0}\right]^{\top}\left[e^{\underline{M}}{ }^{\top}\left(t_{f}-t\right) \underline{N}_{f}^{\star}\right] \\
& =\underline{N}_{0}^{\top}\left[e^{M^{\top}}\left(t-t+t_{f}\right)\right] \underline{N}_{f}^{*}
\end{aligned}
$$

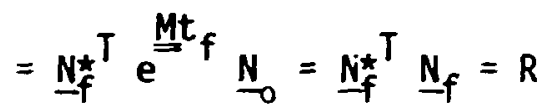

This result was derived earlier, as a conservation law for the total "value" of the nuclide field.

One of the more ouzzling difficulties encountered in providing adjoint capability for the ORIGEN code erose in the treatment of nearly stable (both in decay and in reaction) product nuclides such as $\mathrm{He}^{4}, \mathrm{H}^{2}$, etc. When the parent-daughter relation among nuclides is reversed by transposing $M$, it is possible for nuclides which previously had no daughters to have transmutation products, since their parents are then identified as daughters. The presence of a zero (or very small) transition probability for a nuclide with daughter products causes a series of numerical problams in ORIGEN, the final result being a "divide check." 
The solution to this problem is discussed below, for a hypothetical decay chain of three nuclides - A, B, C - the last of which is stable. He assume the appropriate burn-up equations are the following:

$$
\left[\begin{array}{ccc}
{ }^{-\lambda_{A}} & 0 & 0 \\
\lambda_{A B} & -\lambda_{B} & 0 \\
0 & \lambda_{B C} & 0
\end{array}\right]\left[\begin{array}{l}
N_{A} \\
N_{B} \\
N_{C}
\end{array}\right]=\frac{d}{d t}\left[\begin{array}{l}
N_{A} \\
N_{B} \\
N_{C}
\end{array}\right]
$$

The adjoint system is

$$
\left[\begin{array}{ccc}
-\lambda_{A} & \lambda_{A B} & 0 \\
0 & -\lambda_{B} & \lambda_{B C} \\
0 & 0 & 0
\end{array}\right]\left[\begin{array}{c}
N_{A}^{*} \\
N_{B}^{*} \\
N_{C}^{*}
\end{array}\right]=\frac{-d}{d t}\left[\begin{array}{c}
N_{A}^{*} \\
N_{B}^{*} \\
N_{C}^{*}
\end{array}\right]
$$

The equation for $N_{C}$ is

$$
\frac{d}{d t} N_{C}^{\star}=0 \quad N_{C}^{\star}=\text { constant }
$$

Therefore $N_{C}=(\underline{h})_{C}$, where $\underline{h}$ is the input realization vector. Since this value is fixed by the specified final condition, the calculation of stable-nuclide adjoints is omitted from ORIGEN.

Considering Eq. (A14) again, and omitting the equation for $N_{C}^{\star}$,

$$
\left[\begin{array}{cc}
-\lambda_{A} & \lambda_{A B} \\
0 & -\lambda_{B}
\end{array}\right]\left[\begin{array}{l}
N_{A} \\
N_{B}
\end{array}\right]=\frac{-d}{d t}\left[\begin{array}{l}
N_{A} \\
N_{B}
\end{array}\right]-\left[\begin{array}{c}
0 \\
(\underline{h})_{C} \lambda_{B C}
\end{array}\right]
$$

Thus we see that a stable nuclide can give rise to a fixed source term in the adjoint burn-up equation, depending on the value of $\underline{h}$.

In summary, Eqs. (A7) and (A8) can be incorporated into the ORIGEN to allow adjoint solutions, with four modifications: 
a) enter "initial" charge as $\underline{N}_{f}^{*}$, the response realization vector,

b) reverse the parent-daughter relationship among nuclides,

c) reverse flux and time arrays,

d) interpret all results backwards in the time variable.

With these modifications, as weli as several changes in the numerical methods, the ORIGEN code is called ORIGEN-A, which is presently in use at ORNL. 
APPENDIX B. Origen-A nescription

The ancestry of tne ORIGEN-A Code goes back several gererations. ORIGEN-A is the result of modifications made by $M$. L. Williams to the ORIGEN-S program soon to be reileased as part of the SCALE computer code system. ${ }^{25} 0$. W. Hermann was the main author of ORIGEN-S, wiich represented an updated version of the original ORIGEN Code written by $M . J$. Bel1. The most important new features in ORIGEN-S over CRIGEN was the addition of variable dimensioning and of FIDO input ${ }^{25}$ capability.

The input to the ORIGEN-A Code is nearly identical to that for ORIGEN-S, except for a few adjoint input parameters. The input description in APPENDIX $C$, was originally written by Hermann for ORIGEN-S, with a description of the required adjoint parameters added for this publication. The new input required for adjoint calculations is marked with an asterisk in the margin.

The modifications made to the ORIGEN-S computer program are listed below:

B.1. ORIGEN-A: New and Modified Subroutines Added to ORIGEN

XNUDATA - Transposes light element, fission product, and actinide libraries.

XORIGEN - Prints forward or adjoint field by nuclide and time interval

- Initializes adjoint arrays

- Reverses time and flui print for adjoint calculation

- Calls adjoint source routines

FLIP - Reverses the order of 1-0 arrays

BLADJ - Sets up base locations for stable-nuclide adjoint source

MSBF - Multiolies portion of adjoint source by flux at each time step

ADJSRC - Constructs stabie nuc! ide source

- Deletes stable nucilide data from nuclear data matrix 
APPENDIX C. ORIGEN-A Code Input (Using FIDO)

The ORIGEN-A Code determines the forward concentrations or the adjoint for elements or isotopes that are present after various time durations. These calculations miy consider only the effact of radioactive decay or the effect of irradiation and decay within a given reactor flux.

An interpretation of certain words and phrases used in the input instructions is presented first. Reference to these somewhat arbitrary definitions may enhance some of the explanations in the input description. This description was modified from the original ORIGEN-S input description written by $0 . \mathrm{W}$. Hermann for the ORIGEN module of the SCALE code system.

\section{C.1. Cases and Subcases}

The input data for a job may contain stacked "cases" and "subcases" as described here.

A "case" is defined as that part of a job which includes al! of the problems solved after starting with both a different nuclear library and new material concentrations, unless the "blending feature" is used. The flag, $N G D$, is used to specify the type of the next problem. If $N G D=0$, the following froblem uses both new concentrations and a different ?ibrary. If $N G \emptyset=0$ and $N D B L N D=1$ (the flag set for no "blending"), the next

problem is the start of a new case.

If a "blending case" is requested (specified by NQBLND > 1), even a problem starting with both new concentrations and a different library can be a subcase of the blended case. A new case starts after $N \hat{u} \emptyset=0$, only if the number of subcases where KBLEND was set positive equals the value of NDBLND.

\section{C.2. Nuclide or Isotope Identification Number}

A six-digit "nuclide" integer is used to identify each isotope, including its isomeric state. This is called a "Nuclide ID No." in the input instructions. The following equation is used:

ilucl ide ID No. $=I Z * 10000+I H * 10+$ IS 
where,

$I X=$ the atomic number,

Ii = the atomic weight,

IS $=0$, for ground state,

IS $=1$, for metastable state.

Is > 1 , for additional metastable state leveis.

\section{C.3. Hain Features of the Code}

The code solves problems having the following characteristics or features:

1. An "irradiation" problem is solved using a set of initial nuclide of element concentrations and the "nuclear data library" for a given reactor $f l u x$.

2. A "post-irradiation" problem is solved. It may be part of irradiation subcase or a new subcase.

3. A "decay-only" problem is solved, involving no irradiation.

4. A problem is solved using "continuous feed" feature, where the concentrations are ennanced with a continuous rate of feed for giveri isotopes. This applies to fluid fuel reactors.

5. A prnhlem is solved using "continuous chemical processing" feature, in.ere the concentrations of given elements are depleted by a continuous removal rate through chemical processing.

6. A "continuation" problem may be requested, where an irradiation or decay subcase begins with the concentrations prevailing at any time specified during the last subcase.

7. Either the same nr a different "nuclear data library" may be requested in a continuazion subcase. This allows for different flux spectra or an "experiment position change" within a reactor.

8. A continuation problem is solved using "batch removal" feature, where given fractions of specified elements are removed through chemical batch processing before calculation continues.

9. A "blending case" is executed, which always will contain several subcases. Different concentrations are used in two or more of the subcases. A given fraction of the material from each of the streams, 
or subcases, at specified times are added together to form the initial concentrations for subsequent "blended stream" subcases. While different lioraries are permitted, there may not be any variation in the list of nuclides in the libraries. Any number of problems not related to blending may be solved in subcases within the case, if requested.

10. The output tables of results and libraries are completely optional. The answers may be printed in three types of tables pertaining to the "iuclides" of the three different libraries. Tables may je given for results listed only by "elements" of the libraries. Also. summary tables, including both nuclide and element type tables, may be requested. Lines are deleted from the latter tables, if values are below specified cutoffs. Also, the results at alternate time periods are deleted from summary tables. All of the tables may be "optionally printed" for the nonirradiation period in a variety of units pertaining to quantity, activity, heat, or radiation hazard standards. Irradiation period quantity results may be printed in tables listed by either nuclides or elements. Lines for element results below a requested cutoff are suppressed. The output of any of the tables described above may be separately suppressed. Also, a set of several tables of time dependent fhoton sources and neutron sources may be printed or suppressed.

11. Each of the printed tables for the six library files may be separately suppressed. Also, the library prologue and the list of air and water hazard factors may be omitted. If not required for the case, any of the three libraries may be skipped without changing Job Control Language cards.

12. Various punched-output options are available. Concentrations of all nuclides or totals of a printed output table, ir. various units, may be punched. Sources which may be punched include: final gama sources of light elements or fission produzts, the gamma source at any time period for the three libraries combined, and the alpha-neutron and spontaneous fission neutron sources of the actinides. 
12. The total neutron production and absorption and the k-infinity of the heavy elements for cach time period may be printed for forward cases.

14. The "line gamma source option" may be requested. This feature produces a data set containing the gamma suurce for each fission product nuclide at the end of requested time periods. Each source includes the photons per second for every line (energy level) of the nurlice corresponding to data obtained from the ENDF/B-IV Library, Section 457 (or, any later ENDF/B Library). Also, the integrated fission product gamma source intensity is printed for the time periods requested. Not applicable to adjoint calculations.

*15. An adjoint calculation may be requested by setting JCPT $(10)=1$. In this case, the printed values correspond to the "importance" of the specified nuclides at the specified times. In most cases, the units for initial charge should be gram-atoms (see \$3). Flux (59*) and times $\left(60^{*}\right)$ are entered in the same order as in forward case, but the or _ $r$ of "continuation problems" must be reversed. See "Special Instructions for Adjuint Calculation."

\section{C.4. Estimate of Storage Array Size and Job Region Size}

The URIGEN Code utilizes a technique permitting object-time dimensions, or "flexible dimensions." The user may al locate only the quantity of computer core needed for any specific problem. In order to efficiently use flexible dimensions, an adequate value for the Storage Array Size should be determined. The value used for the Storage Array Size must be supplied as the dimension of the array named "L" and the value of LMAX, which are given in the short FORTRAN MAIN routine in ORIGEN. Then, MAIN is compiled as part of the entire job execution. If a Region Size is required by the computer system being used, it may be found from LMAX and the remaininy core and buffer sizes needed by the code.

The following characteristics in the formula for LMAX may be useful:

1. Some $u_{i}$ the input parameters used in the formula (e.g., IZMAX) may exceed the necessary dimension size, which is not known exactly the 
first time a particular : ibrary is requested. This may cause an unavoidable "over-estimate" of LMAX.

2. A few small parameters are deleted from the formula and replaced with additions to the constants. Although this change causes the caiculation to be slightly inaccurate, it reduces the length of the formula and assures a safe "over-estimate" of LMAX.

3. The actual sizes needed, during execution, for LMAX and the terms $A$ thrcugh $H$ in the formula are printed for each subcase. Proper use of tirese printed values in later jobs using the same parameters may substantially reduce the length of the formula.

4. The calculation requires use of a naximum value of some of the terms in the formula. This is denoted by $\operatorname{MAX}(\ldots .$.$) , similar to FORTRAN.$ If the short comparison test applying to a term is true, the longer computation for the term is not required. (See $A, B$, and C)

5. A default value is shown in each equation. It is the result obtained if all parameters used in the :quation equal the corresponding default values in the input instructions.

6. Aiways use the largest value of LMAX calculated for all subcases within the job. Note that the terms $A, B$, and $C$ are constant for all subcases using the same data library.

$$
\begin{aligned}
\text { LMAX }= & A+\operatorname{MAX}(B, C, H, I)+100=43,860 \text { (defaul } t) \\
A= & (I T M A X+L P U) \star(9-2 \star M P C T A E)+3^{\star}(\text { IAMAX }+L P U)+2 \star I Z M A X \\
& +I L M A X+L P I J+650=15,160 \text { (defaul }) \\
B= & 2 \star(I T M A X+L P U) \star(N R E A C T+M P C T A B+1)+\text { IFMAX } \text { NFIS } \emptyset+2 \star I Z M A X \\
& +8 \star L P U+9 \star N G R P+100=22,200 \text { (default })
\end{aligned}
$$

or,

$$
\begin{aligned}
& B=0 \text {, if } 2 \star(\text { NREACT+MPCTAB })+N F I S \emptyset<15+\text { MQUT } \\
& C=N E N L{ }^{\star}(\text { ILMAX+1 })+\text { NENAC }+(\text { LAMAX }+ \text { LPU }+2)+\operatorname{NENFP\star }(\text { IFMAX }+1) \\
& + \text { ITMAX }+200=15,270 \text { (defaul } t)
\end{aligned}
$$

or,

$$
\begin{aligned}
C= & 0, \text { if MAX(NENLE, NENAC,NENFP })<20+\text { MDUT } \\
D= & (\text { I MMAX }+L P U+3) \star(M D U T+8)+M P R \emptyset S *(N P R Q S+2)+2 \star N S H R T \\
& +3 \star N T E R M+100=15,750 \text { (default }) \\
E= & 2 \star(I T M A X+L P U), \text { if NOBLND }>1
\end{aligned}
$$


or,

$$
\begin{aligned}
& E=0 \text {, if } N 9 B L N D=1 \text { (defaul } t) \\
& F=2 *(I Z M A X+4 * L P U)+8 *(\text { ITMAX }+L P U)+N T E R M=12,850 \text { (default) } \\
& G=(\text { MAX (NENLE, NENAC, NENFP })+8) \star(\text { MUUT }+2)+\text { MAX (NENLE } \star \text { ILMAX, } \\
& \text { NENAC } \star \text { (IAMAX +LPU), NENFP*IFMAX) }=6,312 \text { (default) } \\
& H=D+E+H A X(F, G)=28,600 \text { (defaul } t \text { ) } \\
& I=I T M A X+\text { NELEM + NIMAX + 2*N2MAX + MPUT }
\end{aligned}
$$

If a Job Region Size is required, it is derived from LMAX. When using the current computer system at ORNL (10-1-74), the following formula may be used:

Region Size $=(84+4 \star$ LMAX/1024)K Bytes

ॠ7. Adjoint calculations require 2,000 additional words for data storage.

\section{C.5. Data Sets Required and Unit Assignments}

The following table gives information concerning data sets needed for Job Control Language. The data sets are referred to by their variable name in the code. If the unit number is defined in the input, the name of the array in which it may be entered is indicated. If the unit number is always set by the code, its value is shown. Also, any other necessary information is given.

Data Set Unit Assignmenis

$$
\text { Name Unit }
$$

N5

N6
$5 \quad$ All input data cards.

6 Printed output giving "FIDQ data edit" of array entry lengths for data read prior to processing library.
KQUT
HOUM
9
Same as function of $N 6$ for all cards read after processing library. If KOUT $=t$, the pages printed from unit 9 follow those from unit 6 . $3 \$$ Printed output of ORIGEN Code, excluding FIOD data edit. 
Data Set Unit Assignments (Continued)

Name Unit $\quad$ Function and Comments

NUSET $\quad 3 \$ \quad$ Nuclear Data Library which contains one to six files or data sets, depending on method produced. (See ORNL-4628, Section 3)

NDISK 11 Unformatted (binary) scratch data set, usually on a disk. Space allocation should accommodate (in bytes) four times the value of " $C$ " in Storage Array Size Formula. BLKSIZE = 1000, usually, is reasonable. Larger values may require an increase in Region Size.

NPUN $56 \$$ Punched output of ORIGEN Code. If punched cards are not requested ( $M P U N=0$ ), the data definition card is not needed.

NDF $81 \$$ ENDF/B Library, needed if using gama source option (LNGAM = 1 in $81 \$$ Array).

$\star J D P T(11) \quad 54 \$ \quad$ If JDPT(11) $=N$, nuclide adjoint or forward concentrations will be written on Logical Unit N. A separate record is written for each time step; each record is "number of nuclides" long.

LDSET $31 \$$ Unformatted (binary) data set for the gamma sources produced. Need if LNGAM $=1$ in $81 \$$ Array. See below for the data set format.

C. $\overline{0}$. Format of LDSET - The Gamma Source Data Set

A Gamma Source Data Set, written in the binary mode, call be produced in forward calculations. If LNGAM - 1 (see $81 \$$ Array), this data set is requested. The records are described as folluws (word length is 4 bytes -single precision):

Record No. 1 - 20 words.

Copy of the tiile rard (read after Data Block 6) for the first time period in which gamma source is requested. 
Resord *o. 2 - 4 words, all integers except no. (2).

1. Nuclide ID No. of first fission product

2. Sum of the photons/second for the nuclide

3. Number of lines in the nuclide garma spectrum

4. Number of words is next record, or, twice (3)

Record No. $3-$ no. of words $=$ value of word 4, all are floating point.

1. Line energy (MeV) in gamma spectrum

2. Photons/second for line (1) after time period

continued pairs of line energy and gamma decay rate for all lines in garma spectrum of nuclide.

Record No. 4 - 4 words

Same as Record No. 2 for next fission product nuclide in the ENDF/B file.

Record No. 5

Same as Record No. 3 for Record No. 4 nuclide.

(Continued for all fission product nuclides in ENDF/B file.:

Last Record (for this time period) - 4 words

Read same as Record No. 2 with all integers except (2).

1. A zero

2. Total photons/second for all the above nuclides

3. A zero

4. A zero

All of the above records are repeated in the sar.e file for all other requested time periods. 


\section{c.7. GRIGEN-A Input Instructions}

MTE: Default values are given in parentheses. (Assume data required unless a condition is sperified.)

Data Block 1 - New Case Trigger

05 - Hake 5th entry equal to "NDSET" in $3 \$$

$15-$ - (1 entry)

MBLND $=0 / 1 / N$ job terminator $/$ no blending $/ N$ streams blended.

$T$ - terminator

Data Block 2 - New Library

TITLE - Title. Format (20A4)

$2^{\star}$ - Required if MBLND > 1. (NOBLNU entries)

FACT = fraction of each blended stream.

35 - Library Constants. (33 entries)

1. NDSET = library unit no. (27)

2. MIIB $=$ no. of libraries in NDSET.

3. NTYPE $=0 / 1 />1$ card image/binary/future type library.

4. NGRP $=0$, if NTYPE $=0$ or 1 .

$=$ no. of energy groups in cross sections. $(9 \%$

5. KQUT = printed output unit no. (6)

6. $\triangle P C T A B=0 / 1$ air, water hazards requested/not requested.

7. $I N P T=0 / 1$ read photon library from NDSET/cards.

8. $I R=1 / 0$ print transition matrix/do not print. (0)

9. $\mathrm{LPU}=0 / 1$ read all actinide data from NOSET/part from cards. (0)

10-15. NN1, NN2, NN3, NN4, NN5, NN6:

NNI $=1 / 0$ print Ith library table/do not print. (0)

†6. NN7 = Triger for concentration units in 74* Array $(0)$ :

$=0 / 1 / 2 / 3$ unics in gram-atoms/wt. ppm/grams/atom ppm. (Make 0 for adjoint calculation)

17. NN8 $=-1$, suppress print of library prologue;

$=0$, print wanted. $(-1)$

18. I TMAX = total no. of library nuclides

19. ILMAX $=$ no. of kind 1 nuclides. (500:

20. IAMAX $=$ no. of kind 2 nuclides. (120) 
21. IFMAX $=$ no. of kind 3 nuclides. (500)

22. IZMAX $=$ no. of off-diagonal matrix elements. (3000)

23. NREACT $=\max$. no. of reactions for any nuclide. (7)

24. NFISG = no. of fission isotopes.

25. NELEM = max. atomic no. in calculation.

26. $N$ month in date of library.

27. $N D A Y=$ day in date.

28. NYR = year in date.

29. NENAC $=$ no. of actinide photon energy groups. (18)

30. NENLE = no. of light element photon groups. (12)

31. NENFP $=$ no. of fission product photon groups.

32. NREAD $=$ not used. $(0)$

33. MREAD = not used. (0)

4* - Library Constants. (4 entrjes)

1. THERM = ratio of neutron reaction rate of $1 / \mathrm{v}$ absorber to thermal neutron flux. (1.0)

2. RES = resonance flux per unit lethargy/thermal flux.

3. FAST = ratio of flux $>1 \mathrm{MeV} /$ thermal flux. (1.0)

4. $E R R=$ truncation limit. $\left(10^{-25}\right)$

$5 \$$ - Libräy Position Number. (I entry)

NLIBE = Reactor Library position in NDSET (3):

$=1 / 2 / 3 / 4$ for HTGR/LWR/LMFBR/MSBR Reactor (ORNL Library, 10-1-74).

*54\$ - Special Options - not required. (12 entries)

(May include $54 \$$ in Data Block 5)

JPPT = triggers to obtain special option

$\operatorname{JOPT}(I)=N / 0$ request option/not requested. Entry positions

(I) trigger the following: (1) compute K-infinity,

(2) punch concentrations, (3) punch total gamma sources of Kind 1 and 3, (4) punch alpha-n and spontaneous fission sources, (5) punch combined $g$ garma source, (6) punch totals of nuclide tables $N$ of each "Kind", (7) punch for element tables N, (10) perform adjoint calculation (11) write results on $N$. 
$T$ - terminator

Data Block 3 - Actinide Nuclide cards required only if LPU 0.

$6 \$$ - (LPU entries)

NEHCX = NuClide 10 Nos. of actinides read in by cards.

$T$ - terminator

Extra Card Input: If LPU 0 , read $L P U$ cards for cross section data of the NEWCX nuclides.

Data Block 4 - Photon Energy froup Structures. First data array is required, always

355 - Required. (1 entry).

LFLAG $=0$, if default photon energy group structure and U-235 fission photon distribution. to be used as given in original ORNL Libraries $(10-1-74)$.

$=1$, if any group structures read in this data block.

36* - Optional. (NENAC entries)

EACTGP = Actinide photon energy group structure.

37* - Optional. (NENLE entries)

EGROUP = Light element photon energy groups.

38* - Opticnal. (NENAC entries)

SFGAMA = Photons/fission for U-235 in siructure of EACTGP.

39* - Optional. (NENFP entries)

EFPGRP = Fissicn products photon energy groups.

$T$ - terminator

Extra Card input: If INPT - 1, read in entire photon libraries. (fixed format)

Data Block 5 - New Subcase with sarie library

$56 \$$ - Subcase inteyer Control Constants. (20 entries)

1. MNN = no. of irrailiation intervals. (0)

2. MOUT = no. of time intervais in subcase;

$=0$, job terminator. (10)

*3. INDEX $=0 / 1$ power read in $58 * /$ read flux in $59 *$.

(Make $l$ for adjoint calculation)

4. NTABLE $=0$, any output printed if not suppressed in 65\$;

$=1$, print summaries of "Class 3", per $65 \$$. 
5. MSTAR = time period for CUTOFF, photon sources. (0)

$=0$, cut off feature not used, and JTP -1 or 4 .

6. NGP = Next problem indicator (0):

$=-1$, new concentrations and same library;

$=0$, new concentrations and ibrary;

$=1$, old concentrations and same library;

$=3$, old concentrations and new library.

7. $\operatorname{MPRQS}=0$, for no continuous chemical processing;

$=N$, for $N$ groups of elements continuously processed. (0)

8. NPRQS $=0$, if $M P R O S=0$;

$=K$, the max. no. of elements in a process group.

9. $M F E E D=0$, for no continuous feed;

$=N$, if $N$ elements are continuously feed.

10. MSUB $=0$, for new concentrations (Last $N G=-1$ or 0 );

$=N$, if old concentrations are from time interval $N$;

$=-N$, where $N$ means the same, but with batch processing. (0)

11. KTERM = max. no. of exponential expansion terms.

12. NSHRT $=$ max. no. of short-lived precursers in chain. $(100)$

13. NXCMP $=$ no. of new nuclide or elenent concentrations. (0)

14. NUNIT $=1 / 2 / 3 / 4 / 5 / 6$ time (in 60*) in sec./min./hrs./days/ yrs./other.

15. NTI $=0$, no title cards read at Data Block 6;

= 1, TITLE read;

= 2. BASIS read;

$=3$, both are read.

16. NPUN $=0 / N$ no punch/punches concentrations on unit $N$.

17. JTO =0, all non-irradiation tables output;

$=1$, all output results suppressed;

= 2, may suppress only by $65 \$$ or $66 \$$;

= 3, suppresses all except photon tables;

$=4$, suppresses photon tables and by $65 \$$ or $66 \$$. 
18. NUC $=0$, suppresses "irradiation" nuclide tables;

$=1$, suppressed only by $66 \$$. (0)

19. NEL = same as NUC for element tables.

20. $\mathrm{KBLEND}=-1$, if subcase uses total of previous blended s treatns;

$=0$, no blended strean saved or used;

$=\boldsymbol{N}$, concentrations at time period, $N$, multiolied times next value of FACT are added as part of blend. (0)

57* - Subcase Floating Point Constants. (5 entries)

1. TT = code uses $T(1)-T$ as first interval in calculation. Code sets to 0.0 at start or after $N G=0 .(0.0)$

2. RH = total material density ( $g m . / \mathrm{cc}$.). Needed for tables in units of atoms/barn-cm., if NN7 $=1$ or $3 .(0.0)$

3. CUT = an option for deleting elements in tables under o6\$ control. If the concentration in units of $74^{\star}$ is less than CUT for any element, it is deleted. $(0.0)$

4. FRACPN $=(T$ (MAN) - TMO) $/$ (sun of time of all irradiation subcases). (1.0)

5. TCONST $=$ If NUNIT $=6$, no. of sec. in the special time unit. $T$ - terminator

Data Block 6 - Subcase Arrays and Titles

TITLE - Subcase Title, if NTI $=1$ or 3 . Format (20A4)

BASIS - Basis of Calculation, $i=N T I=2$ or 3 . Format (10A4) 58* - Power required if INGEX $=0$ and MAN $>0$. (MMN entries)

POWER $=$ themal power in time intervals of $60^{*}$ (consecutive values or winth value canno $i$ be zero.)

59* Flux required if INDEX $=1$ and MNN 0 . (MMN entries)

fiux $=$ thermal flux in neutrons $/ \mathrm{cm}^{2}{ }^{2}-\mathrm{sec}$., (consecutive values or Month value cannot be zero).

60* Printout Timas. (MDUT entries)

$T \quad=$ elapsed times since start of case. These are printed. See TM. 
61 * Output Cutoffs - required if MSTAR 0 and sumaries in $65 \$$. (7 entries)

CUTOFF = cutoff values for deleting lines from 7 types of sumary tables. This is compared with result at time period MSTAR.

62* - Removal Constants - required if MPROS > 0. (MPROS entries)

PRATE = group removal constants in continuous chemical processing.

$63 \$$ - No. of Eleinents - required if MPRES > 0 . (MPRgS entries) LPPROS = no. of elements being prccessed in each group. 645 - Atomic Numbers - required if MPKOS > 0 . (entries - MPRS* NPROS)

NZPROS = atomic nos. of all processed elements in sets of entries equal to MPRPS. After the corresponding MPPROS elements, remaining entries are " 0 ".

655 Array - Required if [17th] JTO $=2$ or 4. (63 entries) Nig

= an output sippression array for all "non-irradiation" tables except the photon tables or those already suppressed with [4th] NTABLE $=1$ and MPCTAB $=1$ (6th entry in 35 Array):

$=0$, suppresses the table (or the two sumary tables) denoted by the entry position;

$=1$, princs the output for the entry position. (If NN7 $=1$ or 3 , only the first three entries in the set for of each "Kind" have any effect. Tables controlled by other entries are not printed. If NN7 $=1$ or 3, furtiner control of output is specified in 665 Array.)

There are 84 tables controlled with the 63 entries here. Separate tab?es are printed for each of the three libraries. They may be listed according to nuclides or elements. The computed quantities may be given in seven different types of uni:s for a? 1 time periods or alternate time periods. A conve::tion 
is usE. to expliciti; explain this method. First the definitions of "Class", "Type", and "Kind" are given. These words are used to show which table corresponds to ari entry position.

Class $I$ is a table wherc the list is given by nuclides.

Class 2 is 2 table mere the list is given by elements.

Class 3 are two table sumaries of al ternate time periods of nucl ides and elements. (See [5th $\bar{j}$ MSTAR and 61* Array.)

Type 1 table values have units of gram-atoms, if $i m 7=0$ or 2 . (If NW7 $=$ ! or 3 , Type $i$ refers to the three units controlled by or 665 Array.)

Type 2 table values have units of grams.

Type 3 table values have units of curies.

iype 4 tab? a values have units of alpha plus teta plus gamma watts of thermal power.

Type 5 table values have units of garma watts.

Type 6 table values have units of meters of air which diiute to $R C G_{d}$.

Type 7 tabla values have units of meters of water which dirute to $R C G_{1}$.

Kind 1 table nuilides are from Light Eienent iibrary.

Kind 2 table nuclides are from Actinide Library.

Kind 3 table nuclides are from fission Products Library.

The tabie output is controlled by the position of the entry in 655 Array is follows:

Entry 1 refers to Class 1, Type 1, Kind 1.

Entry 2 refers to Class 2, Type 1, Kind 1.

Eritry 3 refers to Class 3 , Type 1, Kind 1 .

Entry 4 refers to Class 1, Type 2, Kind 1.

Entry 21 refers to Class 3, Type 7, Kind 1. Entry 22 refers to Class 1 , Type 1 , kind 2. 
Entry $M$ refers to Class I, Type $J$, Kind $K$ according to the following:

$$
N=I+(J-1) * 3+(K-1) \star 21
$$

Entry 63 refers to Class 3, Type 7, Kind 3.

Or, this follow the Fortrar fer for $\operatorname{kT}(3,7,3)$ :

( ( (NTP(CLASS, TYPE, KIND), CLASS $=1,3)$, TYPE $=1, i), K I M D=1,3)$ ).

6ES Array - Required if [1st] naw 0 and [17th] JTo $=0,2,4$.

(12 entries)

1.

= "irradiation period" output table control optio is. If WW7 $=1$ or 3 ( 35 Array), R also applies to "nonirradiation" output tables.

$=0$, suppresses the table denoted by the entry position;

$=1$, prints the tables controlled by the entry position, except that all tables in a "Class" can be suppressed with [i8th] NUC $=0,[19$ th $]$ NEL $=0$, or suppression in $65 \$$ data. Aiso, elements are deleted from tables as specified by CLT in 57* Array. "Type" units must correspond to those denoted by HN7. If NN7 $=0$ or 2, tables may be printed in Type 1 units, only. An entry for any other table has no effect. If NN7 $=1$ or 3 and using ppm in $74^{*}$ Array, tables may be printed in units of Types 2, 3 or 4 (defined below) and obtained during both the irradiation or non-irradiation periods. (Note, if NN7 = 0 or 2, the entries control tables during the irradiation period only.) Using terms from above (in $65 \$$ Array), define Class 1 and 2 and Kind 1,2 and 3 the same. Use new meaning as follows:

Type 1 table values have units of gram-ators,

Type 2 table values have units of weight ppm.

Type 3 table values have units of atom pprin.

Type 4 table values have units of atoms/(barn-cm).

The tables referred to by the 12 entries positions in $66 \$$ Array are as follows: 
Entry 1 refers to Type 1, Kind 1, Class 1 and 2. Entry 2 refers to Type 2 , Kind 1 , Class 1 and 2 . Entry 3 refers to Type 3, Kind 1, Class 1 and 2 . Eittry 4 refers to Type 4, Kind $i$, Class 1 and 2. Entry 5 referz to Type 1, Kind 2, Class 1 and 2. Entry 6 refers to iyoe 2, xind 2, Class 1 and 2.

Entry 12 refers to Type 4, Kind $\xi$, Class 1 and $\hat{L}$. Hote that no Class 1 nor Class 2 tables are printed unless [1ath] $\mathrm{NUC}=1$ or [19th] $\mathrm{NEL}=1$, respectively.

735 - ID of Nuclides - required for new case or if last wG = 1 or 0. (NXCMP entries)

INUCl = Huclide 10 No. (if NEXI - i, 2, or 3) or Element ID No. (if NEXI - 4, and IH - 0 in ID no.) for the concentrations in $74^{*}$.

74* - Concentrations required with 735. (NXCMP entries) XCGM1 = concentrations for nuclides and elements ir: 735 in gram-atoms (NN7 = 0), wt. ppor : NN7 = 3).

755 - Library Kinds - required with 735. (NXCMP entries) KEXi $=1 / 2 / 3$ where Ruclide ID w. applies to Library "Kind" 1/2/3. $=4$ for element in "Kind" 1 Library. $76 \$$ - ID of Nuclides - required if MFEED > 0 . (MFEED entries) INUC2 = same as INUC1, applied to continuous feed cption. 77 - Feed Rates - required if MFEED > 0 . (MFEED entries) XCoH2 continuous feed rates (gram-atoms/sec./fuel unit). $78 \$$ - Library Kind - required if MFEED > 0 . (MFEED entries) NEX2 = same convention as NEX1, applies to 765 79* = Element Fractions - required if MSUB < $0 . \quad$ (NELEM entries) FREPRD = fractions of elements retained in batch chemical pricessing, wiere entry position no. - element atomic no. 
815 - Garma Source Constants - required if LiKGAM - 1. ( 6 entries)

1. LNGAM $=1 / 0$ gamma source requested/not requested.

2. LDSET = output gamma source unit no. (15)

3. $N D F=E N D F / B$ unit no. $(1 E)$

4. $\operatorname{MNDF}=2 / 1$ - ENDF/B mode: card image/binary.

$\therefore$ NIMAX $=\max$. no. of fl. pt. words in ENDF record. (3000)

6. NaMAX = max. no. of ENDF photon lines. (1000)

E2\$ - Source Triggers - required if LNGAM - 1. (MQUT entries)

$M=1 / 0$ - $i$ Nth entry, request/no request for gamma source at Nth time period.

$T$ - terminator

IA - Source Title Card for each $84 \$$ Array request. Format (20A4).

FQRMT = Variable Format - required if JפPT(2) 0. Format (20A4). Requires 3 cards.

= the format used for concentrations punched on cards.

Terminate job with card containing "END" starting in Column 1.

*END OF INPUT INSTRUCTIONS*

\section{C.8. *SPECIAL INSTRUCTIONS FOR ADJOINT CALCULATIONS}

If an adjoint calculation is performed, certain options in the forward sense are not applicable--such as blending streams, batch chemical processing, gamma-source, etc. These options obviously should not be used for adjoint calculations.

Flux should aiways be specified rather than power (INDEX in 56\$) for adjoint calculations. Otherwise ORIGEN will try to calculate the flux fron the input power using nuclide adjoints rather than nuclide density, with nonsense results. The order in which the time and flux arrays $\left.\left(5^{\prime}\right)^{\star}, 60^{*}\right)$ are entered is the same as in the forward case--the code reverses theise errays internally.

The "initial" charge entered in the $73 \$$ and $74^{*}$ actua!ly corresponds to the response realization vector at the final time of detection (see text). 
Consider the following exampies:

i) For a response corresponding to "Pu-242 atom density at shutdown", $R=h_{P_{U}}{ }^{242} \underline{\mathrm{N}}$, and we have $73 \$ \$ 942420 \quad 74^{\star \star} 1.0$

ii) For a response corresponding to "U-238 capture rate at shutdown",

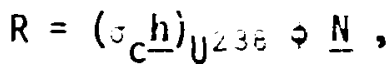

we have

$7355922380 \quad 74^{\star \star}\left(\sigma_{c}\right)_{U}=35 \neq\left(t_{f}\right)$

iii) For a respense corresponding to "Pu-239/N-238 ratio at shutdown", $R=\frac{h_{P_{u}<39} \underline{N}}{\underline{h}_{u} 238 \underline{N}}$

we have

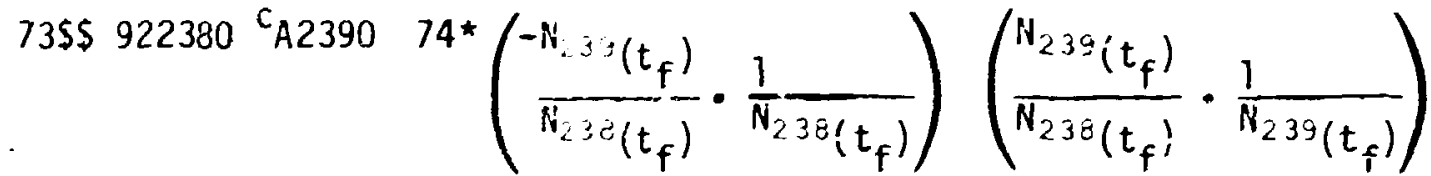

The order of continuation problems siou' 4 be reversed in adjoint calculations. For example, suppose that a computation consisted of an initial calculation from $t=0$ to $t=100$, and a continuation case from $t=100$ to $t=200$. This woulc be accomplished in the forward case ty two calculational steps: in ihe first, int 0 in $57^{\star *}$ array is 0.0 , and the last entry in the $60^{\star \star}$ array is $100 . \bar{u}$; in the second step, TM0=1C:.0 and the last $60^{\star *}$ entry is 200.0 . For the adjoini calculation, the first step has TMO $=100.0$ and the last $60^{\star \star}$ entry is 200.0 , the second step has TMO $=0.0$, and the $60^{\star \star}$ array ends at 100.0 . 
66

C.9. Example Input Description

The following pages present sample input for a forward and adjoint ORIGEN-A calculation. The problem considered is for a fast reactor, operated for 1374 days. The initial change for the forward case is the concentration for a Pu-239 sample with Pu-240, Pu-241, Pu-242, and AM-241 impurities. The charge for the adjoint calculation corresponds to a response of "Am-241 concentration at shutdown."

Note in particular the reversal in the order of the sub-cases for the adjoint calculation. The $59^{\star \star}$ ( $f(\mathrm{l})$ ) and $60^{\star \star}$ (time) arrays are in the same order for the two calculations. 


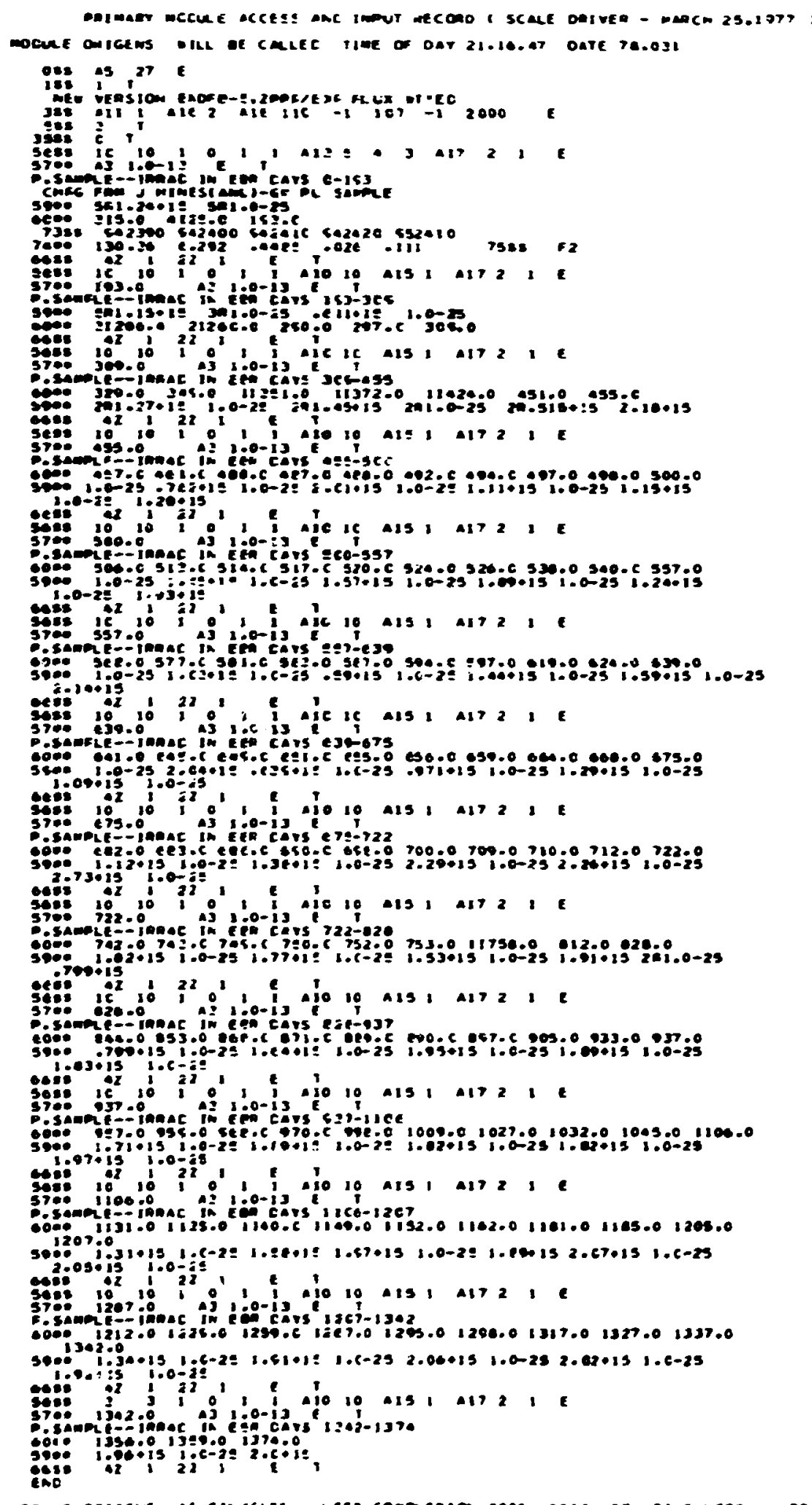

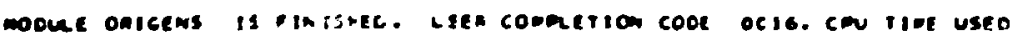


Sample Input for Adjoint Calculation



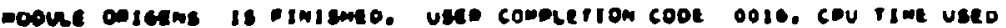


C. 10. Job Control Cards for Local Use of ORIGEN-A

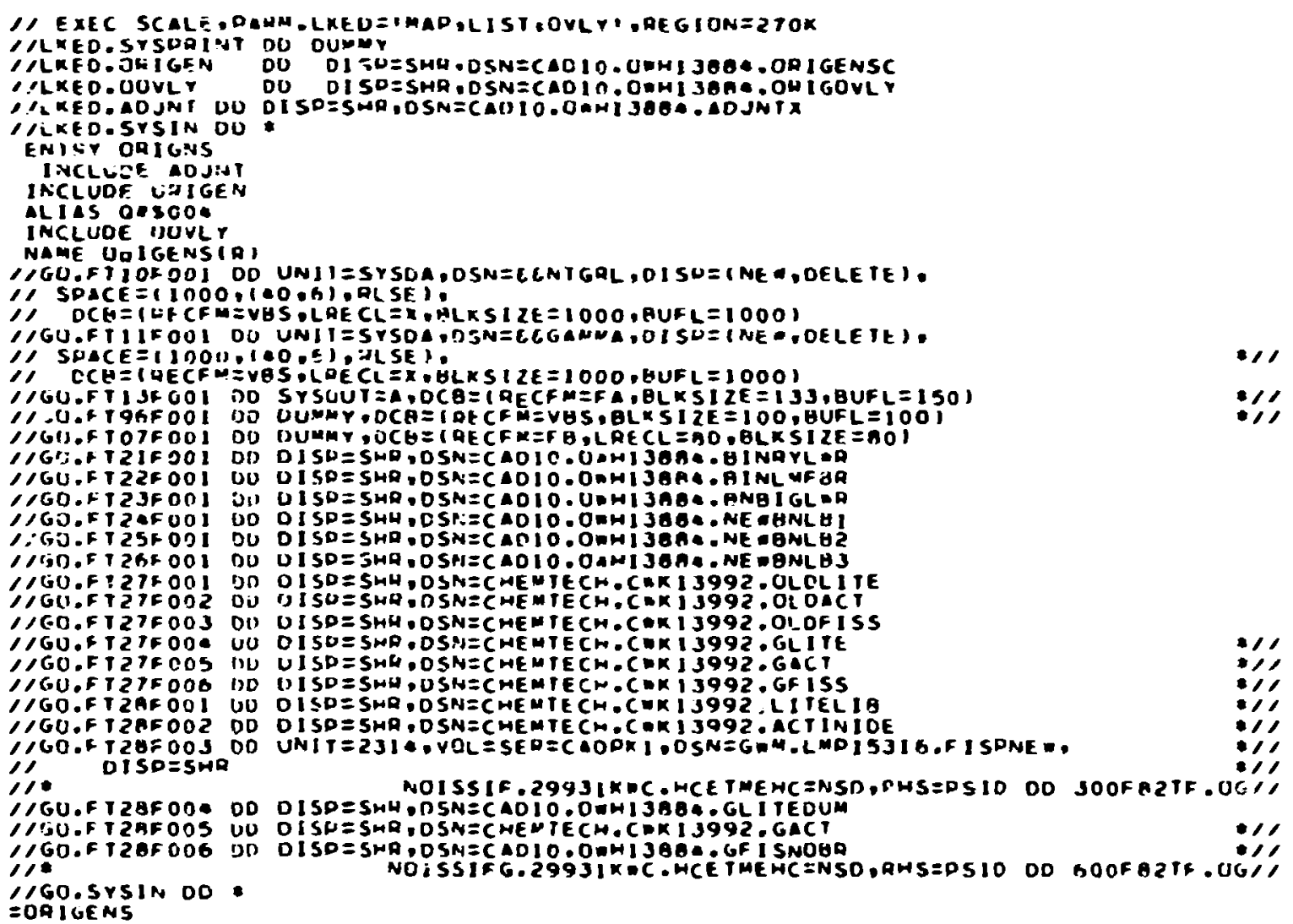




\section{REFERENCES}

1. D. E. Bartine, E. M. Oblow, and F. R. Mynatt, "Neutron Cross-Section Sensitivity finalysis: A General Approach Illustrated for a Na-Fe Sys tem," ORNL-TM-3944 (1972).

2. C. R. Heisbin, J. H. Mara' 2, J. L. Lucius, E. M. Obow, F. R. Mynatt, R. H. Peele, and F. G. Pe -Application of FORSS Sensitivity and Uncertainty Methcdology to Fast Reactor Benchmark Analysis," ORNL/TM-556́3 (1976).

3. E. M. Oblow, "Survey of Shielding Sensitivity Analys is Development and Applications Program at ORNL," ORNL-TM-5176 (1976).

4. H. Humel and H. M. Stacey, Jr., "Sensitivity of A Fast Critical Assembly to Uncertaintles in Input Data Determined by Perturbation Theory," Nurbl. ...: E.r. . 54, 35 (1974).

5. A. Gandini, "Nuclear Data and Integral Measurements Correlation for Fas: Reactors," Parts I, II, and III, RT/FI(73)5, RT/FI(73)2?, and RT/FI(74)3 (1973 and 1974).

6. J, M. Kallfelz, M. L. Williams, D. La!, and G. F. Flanagan, "Sensitivity Studies of the Breeding Ratio for the Clinch River Breeder Reactor." J. M. Kallfelz and R. A. Kai am, eds. Ailianiod

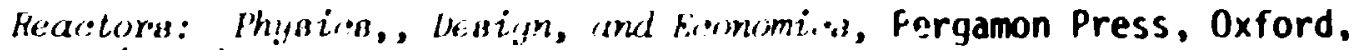
N.Y. (1975).

7. J. H. Marable, J. L. Luctus, C. R. Heisbin, "Compllation of Sensi. tivity Proflles for Several CSEWG Fast Reactor Benchmarks," ORNL-5262 (1977).

8. A. Gandin1. "Time-Dependent Generalized Perturbation Methuds for Burn-Up Analysis," CNEN RT/FI(75) 4. CNEN, Rome (1975).

9. J. Lewins, "Variational Representation In Reactor Physics Derived From a Physical Principle." Nurl. :iri. kin. 8, 95-104 (1960).

10. J. Lewins, "A Time Dependent Importance of Meutron and Precursors." Nucl. Sci. Eng. 7. 268 (1960).

11. A. Gandint, M. Salvatores, and L. Tondinell1. "New Developments in Generalized Perturbation Methods in the Nuclide Field," Nuc:?. Sci. Eng. 62, 339 (1977).

12. M. J. Bel1, "ORIGEN - The ORNL Isotope Generation and Depletion Cade," ORNL-4628 (1973).

13. D. R. Vondy, "Development of a General Method of Explicit Solution to the Nuclide Chain Equations for Digital Machine Calculation." ORNL-TM-361. 
14. E. M. Oblow, "Sensitivity Theory from a Differential ilewpoint," $\therefore 1 . \cdots: \because . \because 359,18 ;-189$ (1976).

15. J. M. Kallfelz, G. B. Bruna, G. Palmiotti, and M. Salvatores, "Eurn-Up Analysis with Time-Dependent Generalized Perturbation Theory," i:a. $\therefore . \therefore$. $\because .62(2), 304$ (1977) .

16. G. C. Pomraning, "Variation Principle for Eigenvalue Equations,"

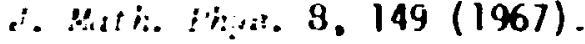

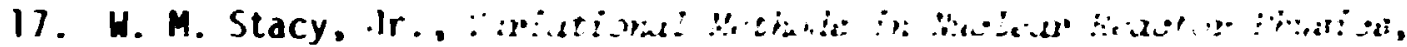
Acadenic Prfss, K.Y., 1974.

18. M. L. Hillians and H. H. Engle, "The Concept of Spatial Channel Theory Applied to Reactor Shielding Analysis," $\because a . \therefore . \because .62$. $92-104$ (19?7).

19. M. L. Hilliams and H. H. Enqle, "Spatial Channei Theory A Method for Determiring the Directional Flow of Radiation through Reactor Systems." Paper P2-13, Proceedinas of fifth International Conference on Reactor Shielding, Knoxvilie. In. 1977.

20. F. G. Perey and 6. CeSaussure, R. B. Perez, "The Formalism for lata Covariance Representation in ENDF/B and Application to the : "IIU Capture Cross Section Sensitivity Study." Proceedings of ANS Topical Advanced Reactors: Physics, Design, fconomics, 1974.

21. H. Henryson, H. H. Humnel, R. N. Hanq, H. M. Stacy, and B. J. Toppel. "Variational Sensitivity Aialysis Theory and Application," FRA-TM-66 (1974).

22. 0. 0zer, personal comunication.

23. C. deSaussure, personal communication.

24. R. Gwin, personal communication.

23. R. M. Hertfall et ai.. "SCALE" A Modular Code System for Performing Standardized Cask-Analysis for Licensing Lvaluation," to be published ds o NUREG document, October 1977.

26. 0. W. Hermann, personal communication. 
ORNL -5393

(ENDF -263)

Distribution Category

UC-34c (Physics-Nuclear)

\section{INTERMAL OISTRIBUTION}

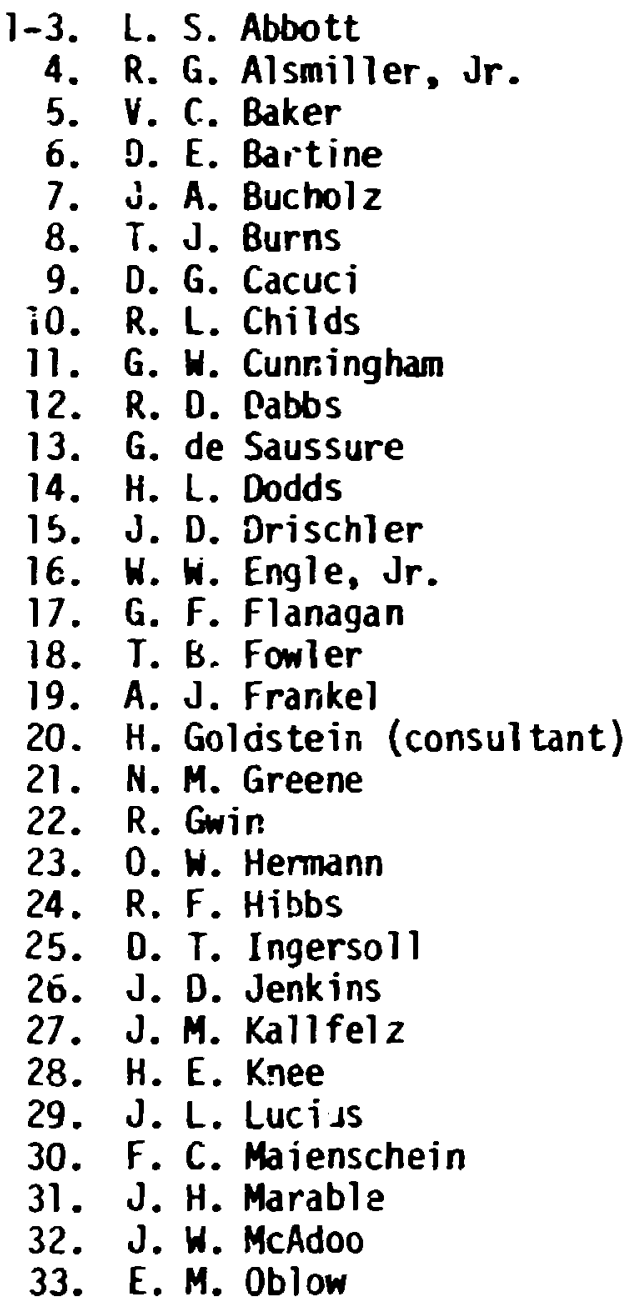

34. R. H. Peelle

35. F. G. Perey

36. R. B. Perez

37. L. M. Petrie

38. H. Pos tna

39. S. Raman

40. H. A. Rhoades

41. J. C. Robinson

42-52. RSIC

53. D. L. Selby

54. P. H. Stelson

55. E. T. Toml inson

56. D. B. Trauger

57. D. R. Vondy

58. C. R. Heisoin

59. R. M. Hestfall

60. J. E. White

61. J. R. Whi te

62. G. E. Whitesides

63-68. M. L. Williams

69. A. Zucker

70. P. Greebler (consul tant)

71. H. Loewenstein (consultant)

72. R. E. Uhrig (consul tant)

73. R. Hilson (consultant)

74-75. Central Research Liorary

76. ORNL $Y-12$ Technical Library Document Reference Section

77-78. Laboratory Records Department

79. Laboratory Records, ORNL RC

S. ORNL Fatent Office

81. 130. NPD Reports Office

\section{EXTERNAL DISTRIBUTION}

131. DOE Oak Ridge Operations, Research ar ' Technical Support Division: Virector

132. DOE Oak Ri,je Operations, Peactor Division: Director

133-134. DOE Division of Reactor Research and Development, Washington, D.C. 20545: Director

135-258. For distribution as shown in T10-4500 Distribution Category $U C-34 C$, Physics-Nuclear

259-350. Brookhaven National Laboratory for ENDF distribution 351-390. EPRI distribution 